\title{
Physiological and Morphological Analysis of Synaptic Transmission between Leech Motor Neurons ${ }^{1}$
}

\author{
BONNIE GRANZOW, ${ }^{*}$ W. OTTO FRIESEN,‡ AND WILLIAM B. KRISTAN, JR. ${ }^{\star, 2}$ \\ * Department of Biology, University of California, San Diego, La Jolla, California 92093 and $\ddagger$ Department of Biology, University of \\ Virginia, Charlottesville, Virginia 22901
}

\begin{abstract}
In the leech Hirudo medicinalis inhibitory motor neurons to longitudinal muscles make central inhibitory connections with excitatory motor neurons to the same muscles. We have used a variety of physiological and morphological methods to characterize these inhibitory connections. The efficacy of the transmission between the inhibitors and the excitors was measured by using three intracellular electrodes, two in the inhibitor (one for injecting current and one for measuring voltage) and a third electrode in the excitor for measuring the resultant voltage changes. We have determined that $\Delta V_{\text {pre }} / \Delta V_{\text {post }}$, or what we have called the transmission coefficient, is $X=0.51$, as measured in the somata of the two cells. Evidence which we have obtained leads us to propose that these inhibitory connections between motor neurons are probably monosynaptic. The synaptic latency is consistent with a monosynaptic connection. In addition, a double-labeling technique, whereby one neuron was filled with Lucifer Yellow and the other with horseradish peroxidase (HRP), was used to determine the anatomical relationship between inhibitors and excitors in whole mounts. This revealed varicosities on the processes of inhibitor motor neurons which appear to make contact with processes of excitor motor neurons. A second double-labeling technique, whereby one neuron was filled with HRP and the other with an electron-dense particulate marker, revealed adjacent processes between an inhibitor and an excitor in electron microscopic thin sections which could be the sites of synaptic contact betwen the neurons. The connections appear to be mediated largely by graded transmitter release from the inhibitory motor neurons. Three different methods were used to demonstrate that synaptic transmission remained in the absence of impulses in the inhibitory motor neurons. These included eliminating the impulse-supporting portion of the motor neuron by pinching off its axon, abolishing impulses by replacing $\mathrm{Na}^{+}$with Tris in the medium bathing the nerve cord, and increasing the threshold for impulse production by raising the $\mathrm{Mg}^{2+}$ and $\mathrm{Ca}^{2+}$ concentrations in the medium bathing the nerve cord.
\end{abstract}

Received July 27, 1984; Revised January 30, 1985;

Accepted February 5, 1985

${ }^{1}$ We thank Dr. Brenda Claiborne and Ms. Georgia Wiseman for technical assistance with the electron microscopy, Dr. Ronald Calabrese for suggesting the use of Tris. $\mathrm{HCl}$ as a substitute for $\mathrm{NaCl}$ in sodium-free saline, Dr. Jonathan Singer for supplying us with Imposil, and Dr. Anne Dutton for assistance in preparing the Imposil. This work was supported by National Institutes of Health Grant NS 14410 to W. B. K. and Training Grant NS 06339-02 to B. G., and by National Science Foundation Grant BNS-81-0243 to W. O. F.

${ }^{2}$ To whom correspondence should be addressed.
The longitudinal muscles of the leech body wall are innervated by both excitatory and inhibitory motor neurons (Stuart, 1970; Ort et al., 1974). In addition to its direct effect on body wall muscle, each inhibitory motor neuron inhibits centrally the excitatory motor neuron that innervates that same muscle. Preliminary evidence indicates that these central inhibitory connections are important in producing the excitatory motor neuron impulse bursts that occur during leech swimming (B. Granzow, manuscript in preparation).

We have examined the nature of this central inhibition and have obtained evidence that supports the following three conclusions: (1) the inhibition is strong, (2) the inhibition is not dependent on the propagation of presynaptic impulses to the synaptic terminals but apparently is mediated primarily by graded depolarization of the presynaptic terminals, and (3) the inhibitory connections are monosynaptic. Proving that a functional connection is monosynaptic (i.e., that cell I contacts cell II directly and not via an intermedicate cell I') is often difficult by conventional physiological criteria when the pathway involves only impulse-mediated transmission (Berry and Pentreath, 1976); these difficulties are compounded when the synaptic connection of concern involves a neuron that releases transmitter as a graded function of membrane potential (Burrows, 1979). In this study we have combined physiological and anatomical approaches in an attempt to establish that the connections from inhibitory longitudinal muscle motor neurons to excitatory longitudinal muscle motor neurons are direst

Materials and Methods

\section{Physiology}

Isolated chains of three to six ganglia of Hirudo medicinalis were used for these experiments. They were pinned out dorsal surface up, in a salineiilled chamber with a transparent floor which allowed for darkfield viewing through a dissecting microscope (Kristan et al., 1974; Ort et al., 1974). Some of the experiments were performed on desheathed ganglia in which the connective tissue capsule enveloping the cell bodies of the ganglia was cut away with iridectomy scissors.

Intracellular recording and current passage were achieved with standard glass microelectrodes filled with $4 \mathrm{~m}$ potassium acetate (resistance of 40 to 50 megohms) connected to high impedance preamplifiers equipped with bridge circuits (Getting, models 4 and 5). Extracellular recordings were made with glass suction electrodes. All signals were recorded on a model A CrownVetter tape recorder. Prerecorded signals were played back at a reduced tape speed and reproduced on a Gould-Brush chart recorder. With this recording system, signals from $\mathrm{DC}$ to $200 \mathrm{~Hz}$ were unattenuated

Normal leech saline solution had the following composition: $115 \mathrm{~mm} \mathrm{NaCl}$, $4 \mathrm{mM} \mathrm{KCl}, 1.8 \mathrm{mM} \mathrm{CaCl}_{2}, 2 \mathrm{mM} \mathrm{MgCl}_{2}$, and $10 \mathrm{~mm}$ HEPES buffer. In Tris- $\mathrm{HCl}$ saline, the $\mathrm{NaCl}$ was replaced by $115 \mathrm{~mm}$ Tris- $\mathrm{HCl}$ (Sigma), neutralized to $\mathrm{pH}$ 7.4 with $\mathrm{KOH}$. In high $\mathrm{Ca}^{2+} /$ high $\mathrm{Mg}^{2+}$ saline, $\mathrm{CaCl}_{2}$ was raised to $20 \mathrm{mM}$, $\mathrm{MgCl}_{2}$ was raised to $10 \mathrm{mM}$, and $\mathrm{NaCl}$ was lowered correspondingly.

\section{Photoinactivation of leech neurons}

Leech neurons were photoinactivated using the technique of Miller and Selverston (1979). Cells were injected intracellularly with Lucifer Yellow, then 
illuminated with blue light (from a 50-W mercury bulb filtered through heat filters and a BG-12 filter) which was focused on the ganglion from beneath the preparation using a mirror and a darkfield condenser. This method of illumination provided an easy means of switching between white light (for normal viewing) and blue light (for photoinactivation) during the course of an experiment. Recordings made from Lucifer-filled neurons during the process of photoinactivation revealed that neurons gradually depolarized and lost the capacity to generate impulses. Illumination periods of up to $20 \mathrm{~min}$ were often required before the membrane potential reached zero. Following photoinactivation of Lucifer-filled neurons, connections between non-filled neurons were also tested to demonstrate that the effects of illumination were limited to the filled neurons.

\section{Double fills}

Light microscopy. To observe pairs of motor neurons at the light microscope level, the double-fill technique of Macagno et al. (1981) was employed. Briefly, one cell was pressure-injected with horseradish peroxidase (HRP; type VI, Sigma) and another with Lucifer Yellow. The ganglia were incubated in diaminobenzidine (DAB; Sigma) in saline and reacted with $\mathrm{H}_{2} \mathrm{O}_{2}$ prior to fixation in paraformaldehyde. This resulted in the usual dark precipitate being formed in the HRF-filled cell while preserving the Lucifer Yellow fluorescence. The ganglia were then dehydrated. cleared, and mounted in methylsalicylate. The two cells were observed and photographed simultaneously on a Ziess Standard fluorescence microscope using a properly balanced combination of epi-illumination (through Zeiss filter unit 48-77-06) and transmitted blue light (light from a tungsten bulb passed through a blue filter).

Electron microscopy. To mark pairs of motor neurons individually for identification in the electron microscope, one cell was injected with HRP and another was injected with Imposil (available under the trade name NOnemic from Burns-Biotec, Laboratories Division, Chromalloy Pharmaceutical, Inc., Omaha, NE). Imposil is a dextran-coated, iron-cored colloid which in the electron microscope appears as rice grain-shaped particles $25 \mathrm{~nm}$ in length. Because of its particulate nature it is readily distinguished from HRP in thin sections. The Imposil is sold as an aqueous solution and contains phenol as a preservative. The solution was prepared for intracellular injection by centrifugation to remove excess dextran followed by dialysis in buffer to remove the phenol. Imposil was pressure-injected into neurons following the same procedure used for HRP pressure injection. Electrodes were pulled from thinwalled filament glass on a Livingston electrode puller. They were backfilled with Imposil $(65 \mathrm{mg}$ of iron/ml) in $0.15 \mathrm{M} \mathrm{KCl}$ buffered with $10 \mathrm{~mm}$ Trismaleate, $\mathrm{pH} 7.4$. The tips of the electrodes were broken to 40 to 60 megohms by gently touching them on a frosted glass surface. The Imposil solution has a brown color which makes it visible as it is injected into a cell body, allowing the progress of a fill to be monitored visually.

After cells were injected, ganglia were left for 15 to $18 \mathrm{hr}$ at $17^{\circ} \mathrm{C}$ in $\mathrm{L}-15$ culture medium supplemented with $3 \%$ glucose and $3 \%$ fetal calf serum This amount of time was necessary for Imposil to distribute throughout the inside of a cell as determined in whole mounts by a histochemical procedure for detecting ferric compounds (Olsson and Kristensson, 1978; NguyenLegros et al., 1980). rollowing tixation, ganglia were incubated in DAB and reacted with $\mathrm{H}_{2} \mathrm{O}_{2}$ as usual to obtain the electron-dense reaction product in the HRP-filled cell. This reaction had no effect on the Imposil. Ganglia were then postfixed in osmium tetroxide and processed for thin sectioning by following the method of Muller and McMahan (1976).

\section{Results}

For the purposes of this paper, the segmentally iterated longitudinal muscles of the body wall of Hirudo will be considered as two functionally distinct sets, the dorsal longitudinal muscles and the ventral longitudinal muscles. This division is functionally applicable to behaviors such as swimming, since it is the alternating contractions in dorsal an ventral longitudinal muscles which produce the body undulations of swimming (Kristan et al., 1974; Ort et al., 1974). In each segmental ganglion, there are four bilateral pairs of dorsal longitudinal muscle excitors (DEs), three pairs of ventral muscle excitors (VEs), as well as two pairs each of dorsal muscle inhibitors (DIs) and ventral muscle inhibitors (VIs) (Stuart, 1970; Ort et al., 19/4). In this report, interactions between four representative pairs of these motor neurons are described: cell 1 (DI), cell $2(\mathrm{VI})$, cell 3 (DE), and cell 4 (VE) (Fig. 1). The notations of DI-1, VI-2, DE-3, and $V E-4$ are used to designate these identified motor neurons throughout this paper.

Somata of leech swim motor neurons do not sustain overshooting impulses. Instead, remotely initiated impulses appear in somata recordings as small, sharp depolarizing deflections ranging in amplitude beteen 0.5 and $5.0 \mathrm{mV}$, depending on the particular motor neuron and quality of the recording. Identification of motor neurons is facilitated by the use of recordings from peripheral nerves (Stuart, 1970; Kristan et al., 1974). DE-3 has the second largest impulse in the dorsal posterior (DP) nerve and is the only dorsal excitatory motor neuron in that nerve to fire phasically during swimming. VE-4 has a large impulse in the ipsilateral posterior posterior (PP) nerve and is the only identified motor neuron on the dorsal surface of the ganglion with an ipsilateral axon. The inhibitory motor neurons are readily identified by the constant positions of their somata, their characteristic impulse shapes, and their inhibitory effects on the excitatory motor neurons.

Upon penetration with an intracellular electrode, the firing level of both excitatory and inhibitory motor neurons varied somewhat, depending both on the state of activity of the nerve cord and on the amount of injury potential caused by the electrode impalement. Usually, good penetrations resulted in stable resting potentials of
Figure 1. Schematic drawing of four longitudinal muscle motor neurons and their functional conncctions. 1 (DI), Dorsal inhibitor; 2 (VI), ventral inhibitor; $3(D E)$, dorsal excitor; 4 (NE), ventral excitor; $D M$, dorsal longitudinal muscte; VM, veritral lungitudinal muscle. $t$, excitatory connections; $\rightarrow$, inhibitory connections; $\uparrow$, electrical connection. For simplicity, motor neurons are shown only for one lateral half of the ganglion although each motor neuron shown has a bilaterally symmetrical counterpart.

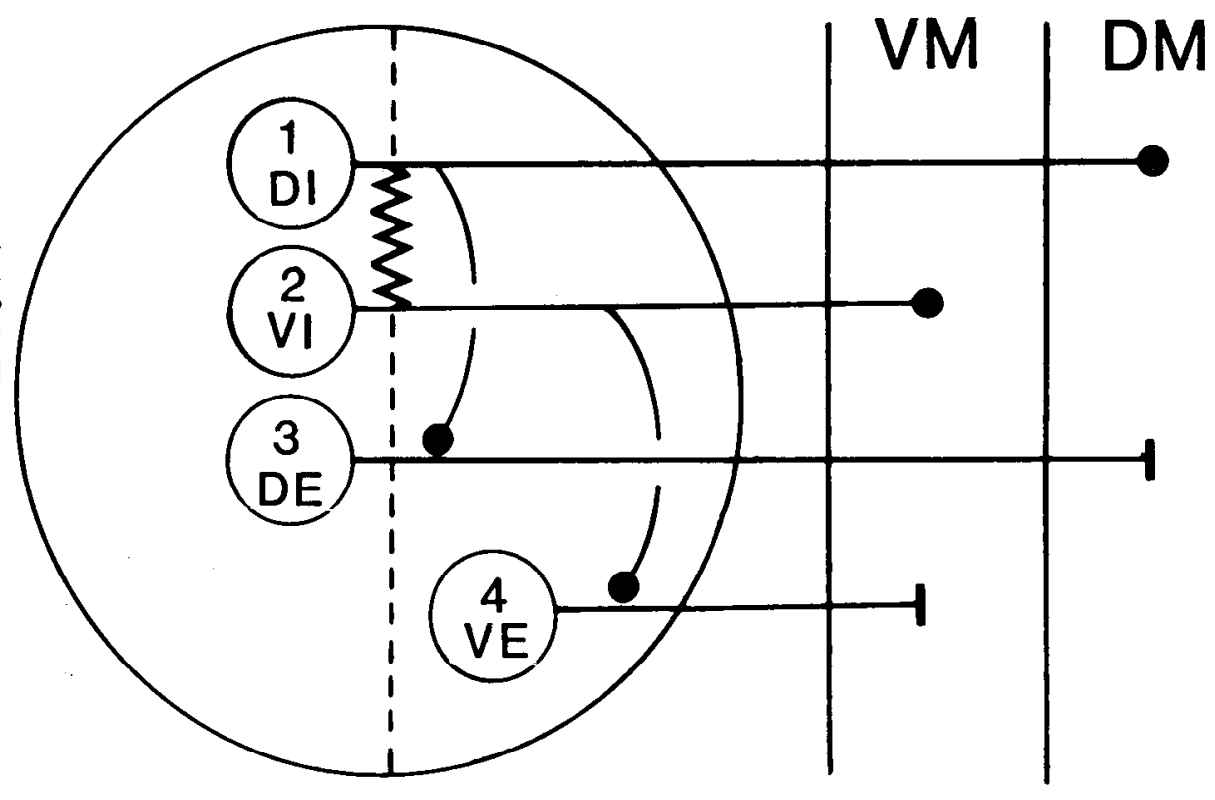


A

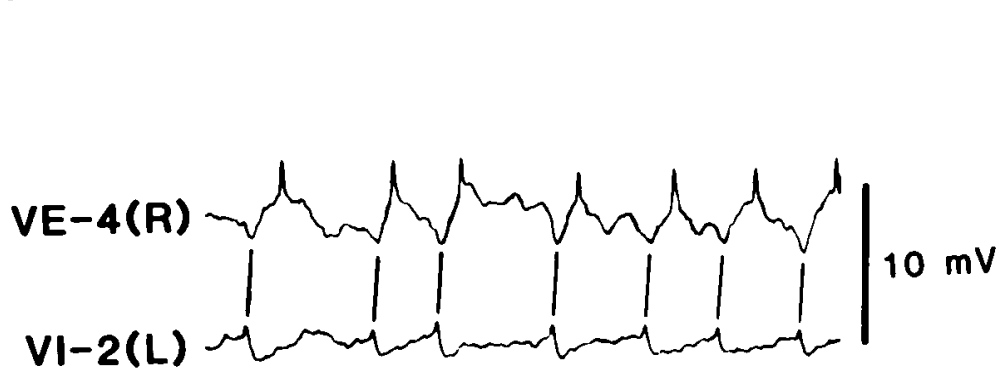

B

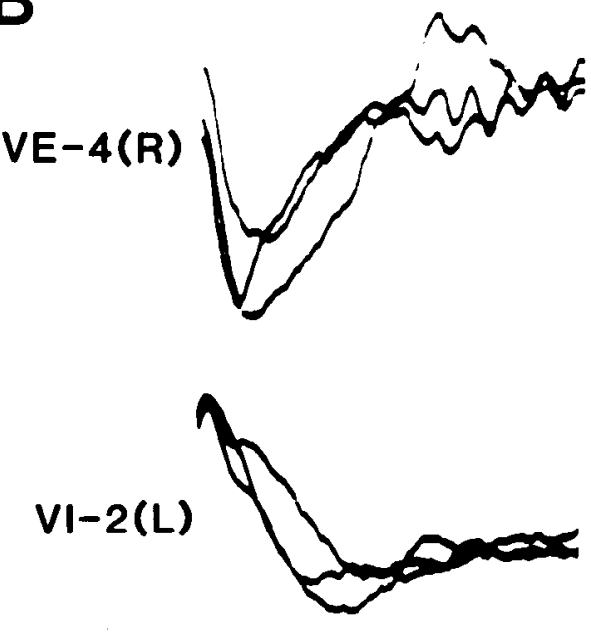

$0.5 \mathrm{~s}$

$10 \mathrm{~ms}$

C

VE-4(R)

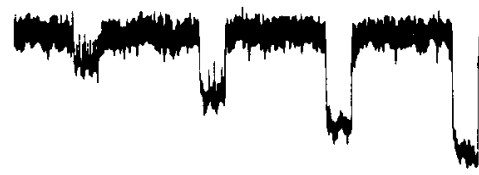<smiles>CC1CCCC1</smiles><smiles>CC[C@H]1CC[C@H]1C</smiles>

$10 \mathrm{mV}$

$\mathrm{VI}-2(\mathrm{~L})$
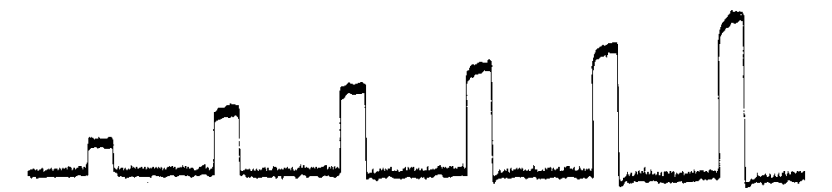

$20 \mathrm{mV}$

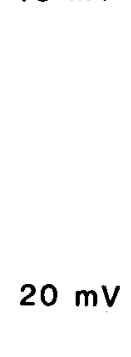

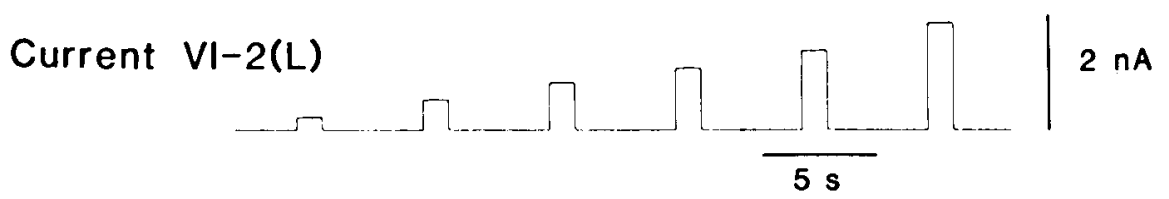

Figure 2. Inhibition of VE-4 by VI-2. A, Impulses in VI-2 (bottom trace) correspond with IPSPs in the contralateral VE-4 (top trace). VI-2 is being held depolarized with a 0.5-rIA current injection to increase its firing rate. $B$, The IPSPS in VE-4 (top trace) follow the impulses in the contralateal V1-2 (bottom trace) with a latency of less than $5 \mathrm{msec}$. Shown are four superimposed traces. C, Depolarizing current pulses injected into VI-2 (middle trace) cause hyperpolarizing responses in VE-4 (top trace) which increase in amplitude with increasing intensities of current injection. The bottom trace is a current pulse monitor.

-40 to $-50 \mathrm{mV}$, spontaneous firing frequencies of about 5 to 10 $\mathrm{Hz}$, and impulse amplitudes of $2 \mathrm{mV}$ in inhibitory motor neurons and $5 \mathrm{mV}$ in excitatory motor neurons (Fig. $2 A$ ).

\section{Functional connections between inhibitory and excitatory motor neurons}

Interaction between $\mathrm{VI}-2$ and VE-4. A one-to-one relationship between spontaneous presynaplic impulses and inhibitory postsynaptic potentials (IPSPS) can be demonstrated consistently between $\mathrm{VI}-2$ and the contralateral VE-4. This relationship also was observed routinely when presynaptic impulses were elicited with depolarizing current injected into VI-2 (Fig. 2A). Using the criteria for monosynapticity of constant and short latency $(<5 \mathrm{msec})$ between the presynaptic impulses and the IPSPS, the connection between VI-2 and VE-4 appears to be direct (Fig. $2 B$ ).

We examined the effectiveness of the VI-2 to VE-4 interaction by passing 2-sec current pulses into VI-2 while recording the membrane potentials of both $\mathrm{VI}-2$ and VE.4. Intracellular injection of relatively srriall depolaricing currents $(0.5$ to $2.0 \Pi \mathrm{A})$ into VI-2 routinely elicited substantial hyperpolarizations of the contralateral VE-4 (Fig. 2C). The time course and amplitude of these hyperpolarizing potentials in VE-4 appeared, in large part, to reflect the DC shift in VI-2 
membrane potential caused by the current injection. This suggests that transmitter release from the inhibitor occurs by way of graded membrane potential changes in addition to the release caused by the presynaptic impulses. The lowest level of presynaptic current injection which produced an observable hyperpolarization in VE-4 was usually around $0.25 \mathrm{nA}$. This lower limit or threshold is apparent only and presumably exists because the synapses mediating the inhibition are too far from the soma of the presynaptic cell to be influenced by current injections of less than $0.25 \mathrm{nA}$. In fact, in many preparations, hyperpolarizing VI-2 beyond "resting potential" resulted in depolarization of the VE-4 membrane potential. This means that transmitter release from the inhibitor often occurs in the absence of depolarization of VI-2 by current injection. Graded increases in the intensity of depolarizing current injected into VI-2 caused graded increases in the hyperpolarizing responses of VE-4 up to a saturation level of approximately 15 to $20 \mathrm{mV}$ of hyperpolarization in VE-4. This level usually was reached when the presynaptic depolarizing current was greater then $2.0 \mathrm{nA}$. The typical relationship between the intensity of depolarizing current injected into VI-2 and the amplitude of the hyperpolarizing response in VE-4 is shown for currents up to $2 \mathrm{nA}$ in Figure $3 A$ (solid circles).

Interaction between $\mathrm{DI}-1$ and $\mathrm{DE}-3$. Depolarization of $\mathrm{Dl}-1$ by current pulses elicited hyperpolarizations of the ipsilateral DE-3 which quantitatively were indistinguishable from that just described for VE. 4 (Fig. $3 B$ ). In contrast, however, individual constant latency IPSPS in $\mathrm{DE}-3$ could not be distinguished in response to $\mathrm{DI}-1$ impulses. Instead, depolarization of Dl-1 caused a smooth hyperpolarization in DE-3 (Fig. 4). The latency between onset of the depolarization of the presynaptic neuron and onset of the postsynaptic response was about $5 \mathrm{msec}$, well within the range of latencies observed for monosynaptic interactions between other leech neurons (Nicholls and Purves, 1970, 1972; Nicholls and Wallace, 1978). Our failure to detect one-to-one synaptic potentials in DE-3 following DI- 1 impulses does not necessarily indicate an indirect connection between $\mathrm{DI}-1$ and DE-3. Instead, anatomical evidence (see "Anatomy") suggests that the IPSPs in DE-3 occur too far from the cell's soma to be recorded as individual events.

Quantitative relationship between pre- and postsynaptic potentials. The quantitative relationship between the presynaptic depolarization caused by current injection into the inhibitor and the postsynaptic hyperpolarizing response in the excitor was determined. In order to do this, one electrode was inscrted into the postsynaptic excitor and two electrodes were inserted into the presynaptic inhibitor, one for injecting current and one for recording membrane potential. Varying the amount of current injected into the inhibitor while recording both pre- and postsynaptic membrane potential changes revealed a linear relationship between presynaptic depolarization and the postsynaptic hyperpolarizing response over a wide range of potential changes in the inhibitor (Fig. 5). The efficacy of the inhibition, which we call the transmission coefficient, is given by the slope of the line $\left(\Delta V_{\text {post }} / \Delta V_{\text {pre }}\right)$ obtained for the linear portion of the data, between 5 and $20 \mathrm{mV}$ presynaptic depolarization. The transmission coefficient was similar for either set of motor neurons, DI-1 and DE-3 or VI-2 and VE-4. The mean value for combined data from all measurements was $0.51(S D=0.10, N=10)$. Given the anatomical relationships between inhibitors and excitors, described below, it is highly likely that the points of synaptic contact between them are at some distance from the somata where potential changes are measured. It seems reasonable to conclude, therefore, that the transmission coefficient at the site of the synapses is even greater.

\section{Indirect interactions between motor neurons}

In addition to the strong inhibitory connections between motor neurons that project to the same longitudinal muscle group (i.e., Vls onto VEs and DIs onto DEs), the inhibitors also produce inhibitory effects on the excitors of the antagonistic longitudinal muscle group;
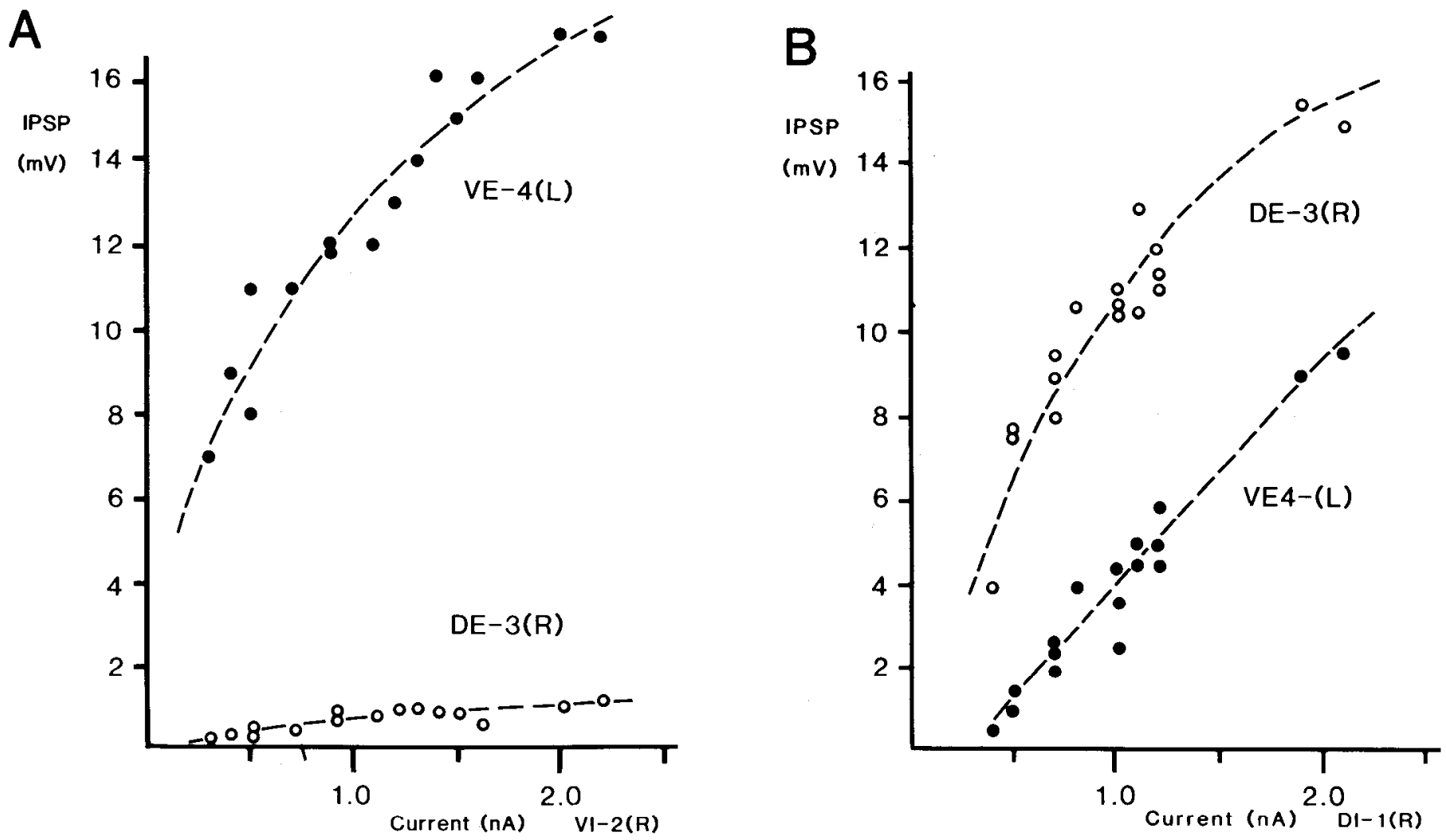

Figure 3. Relationship between the intensity of depolarizing current injected into an inhibitory motor neuron and the amplitude of the hyperpolarizing membrane potential responses recorded simultaneously in both excitatory motor neurons. $A$, Amplitude of the hyperpolarization of the contralateral VE-4 (0) and the ipsilateral DE-3 (O) in response to VI-2 depolarization. $B$. Amplitude of the hyperpolarization of the ipsilateral DE-3 (O) and the contralateral VE-4 (O) in response to $\mathrm{Dl}-1$ depolarization. 


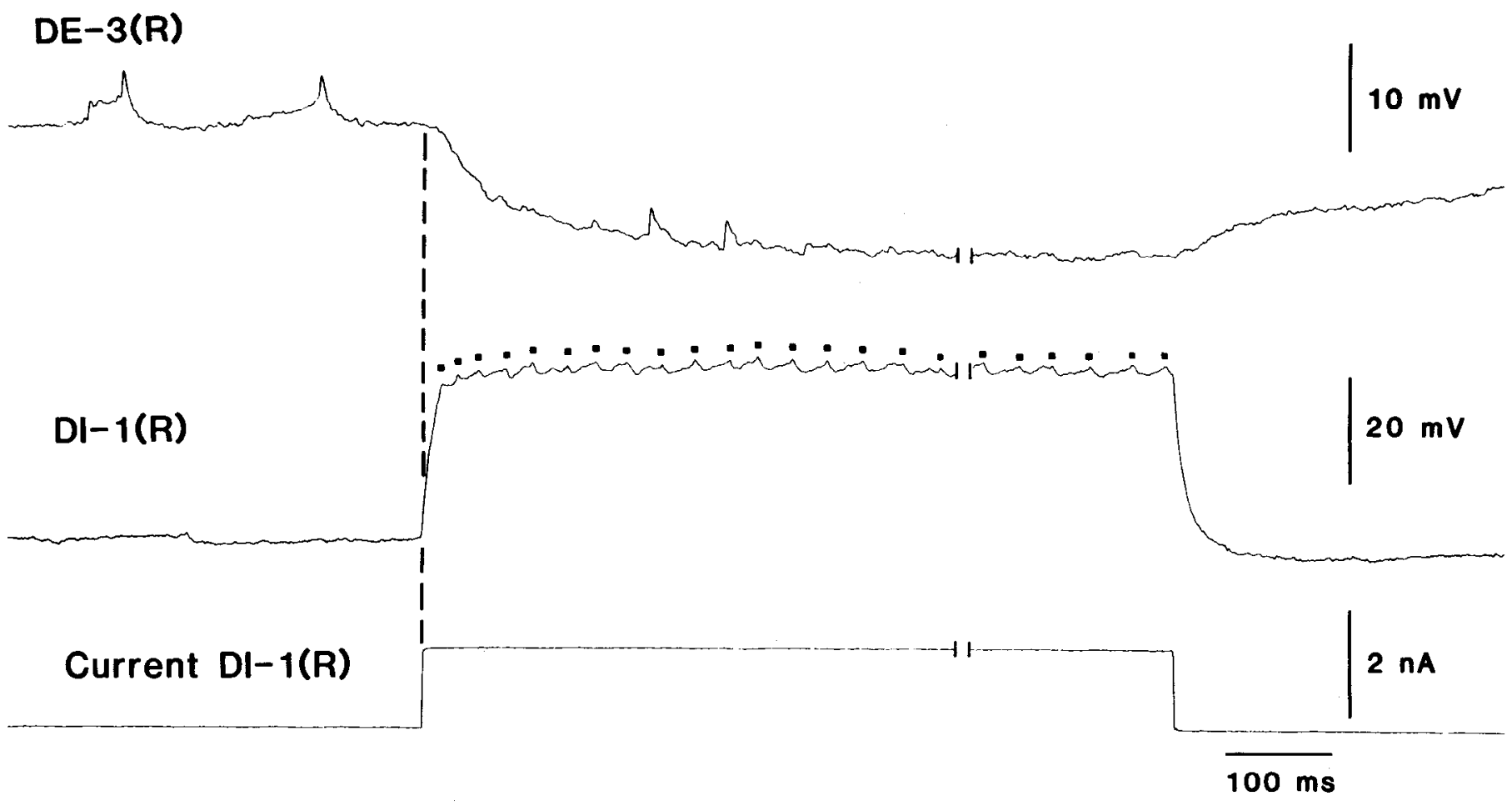

Figure 4. Inhibition of DE-3 (top trace) by DI- 1 (bottom trace) is similar to that which occurs between the ventral inhibtor and the ventral excitor except that there is no obvious corrcspondence betwcen DI 1 impulscs (dots above DI-1 trace) and DE-3 IPSPs. Recordings are shown at a fast sweep speed to demonstrate the short latency between the onset of the depolarization in $\mathrm{Dl}-1$ and the hyperpolarization in $\mathrm{DE}-3$. To make these recordings two electrodes were used in DI-1, one for accurately recording voltage and the other for injecting current. The bottom trace shows the current pulse. The gap in the middle of the traces indicales the excision of 750 msec of the record.
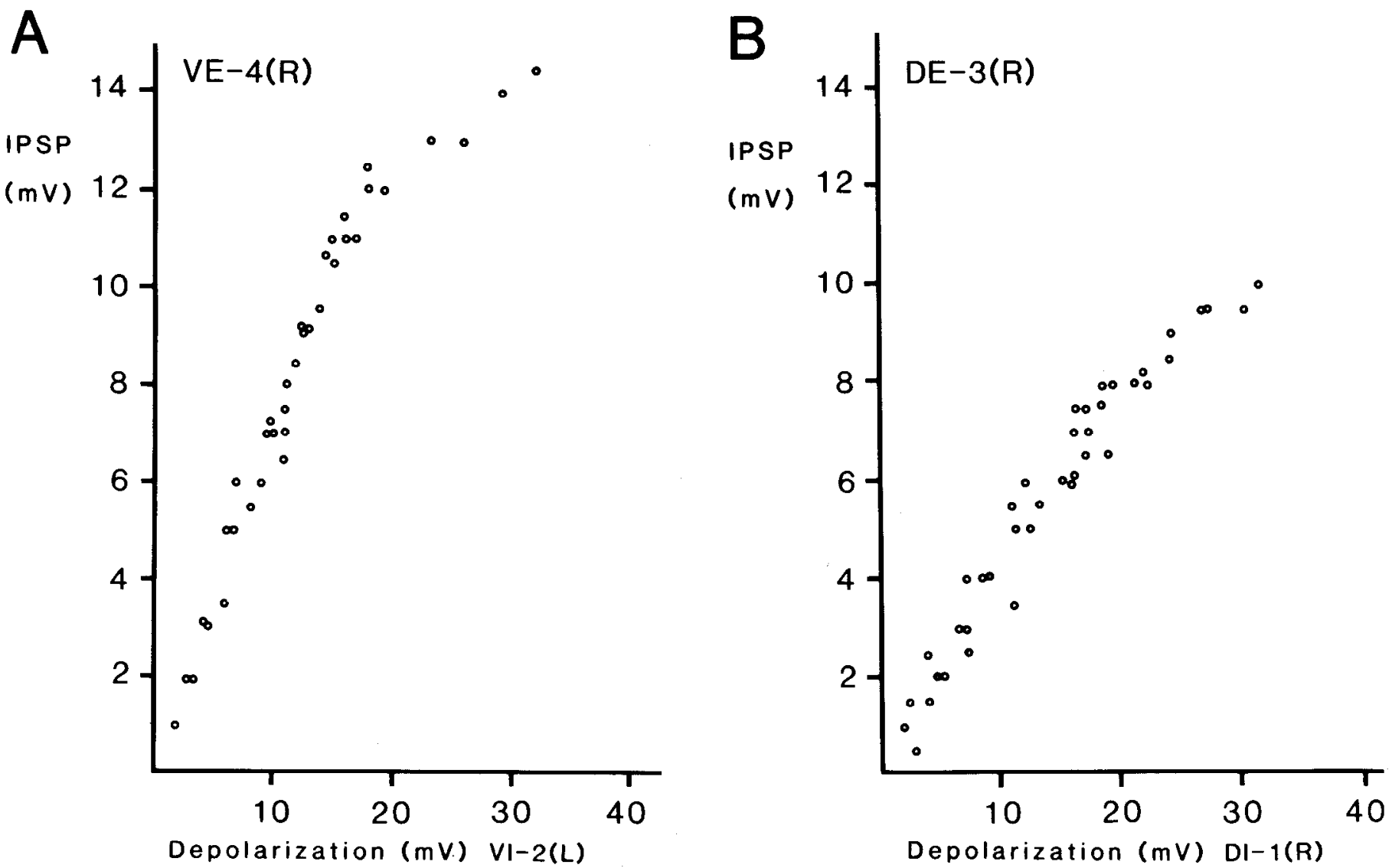

Figure 5. Relationship between presynaptic membrane potential depolarizations of the inhibitory motor neurons (caused by current injection) and postsynaptic membrane potential hyperpolarizing responses in excitatory motor neurons. $A$, Relationship between VI-2 and the contralateral VE-4. $B$, Relationship between $\mathrm{Dl}-1$ an the ipsilateral DE-3. To obtain these data, three intracellular electrodes were used: one for injecting current, a second one to record membrane potential in the inhibitor motor neuron, and a third electrode in the excitatory motor neuron to record synaptic potentials. 
i.e., Vls inhibit DEs and DIs inhibit VEs (Fig. 3). The effectiveness of the latter inhibitory interactions is quite variable, sometimes being comparable to that between similarly projecting motor neurons (Fig. $3 B$, solid circles), although more often being relatively weak (Fig. $3 A$, open circles) and sometimes not observable at all (not shown). This variability and lower efficacy suggest that this inhibition of Vls onto DEs and of Dls onto VEs is indirect. Evidence obtained using two different methods revealed that, in fact, this inhibition is mediated indirectly through electrical coupling beteen DI- 1 and VI-2 (Ort et al., 1974).

The first method employed three intracellular electrodes, one each in $\mathrm{Dl}-1, \mathrm{VI}-2$, and the contralateral VE-4 (Fig. 6A). A series of short

A

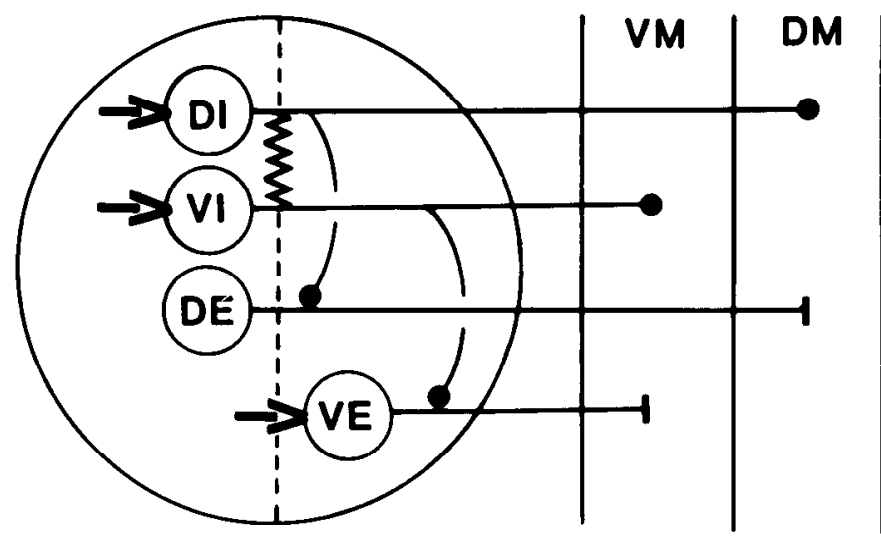

B

$V E-4(R)$

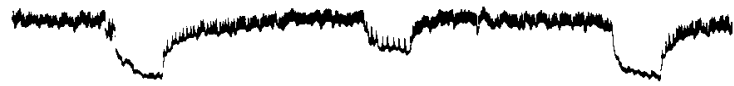

num
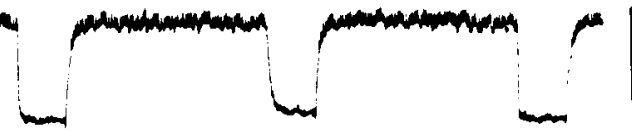

$20 \mathrm{mV}$

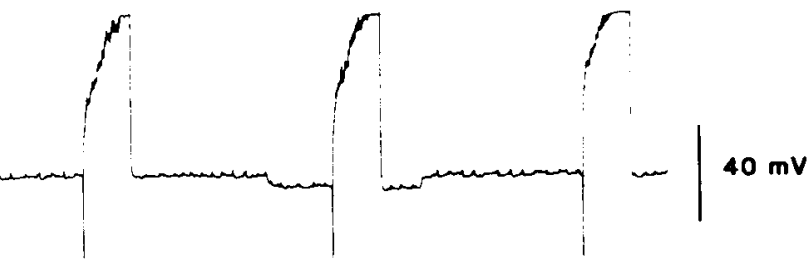

$\mathrm{DI}-1(\mathrm{~L})$
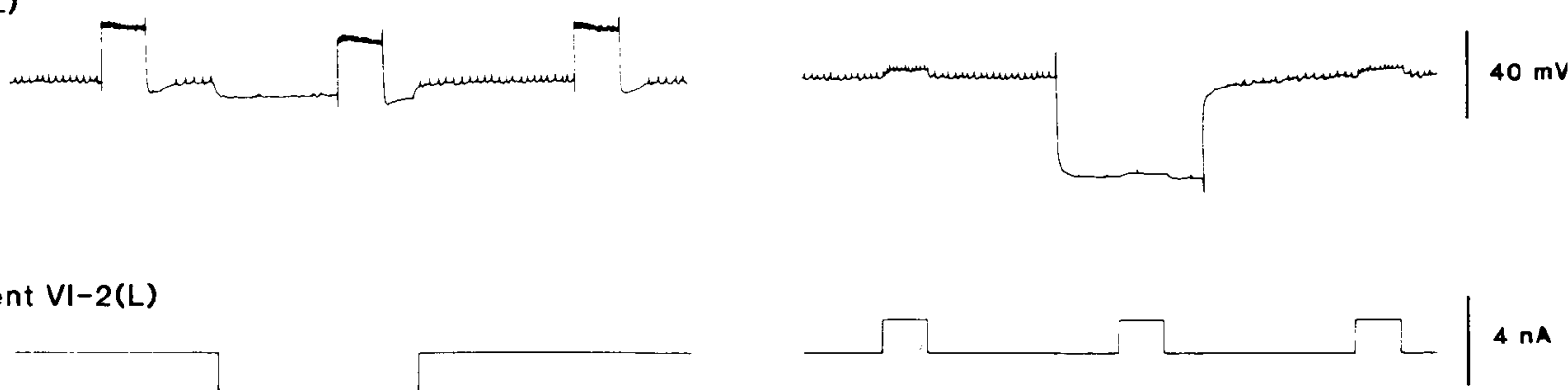

Current $\mathrm{VI}-2(\mathrm{~L})$

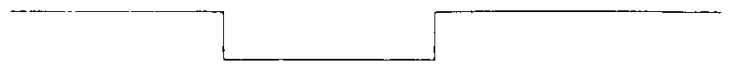

\section{Current DI-1(L)}
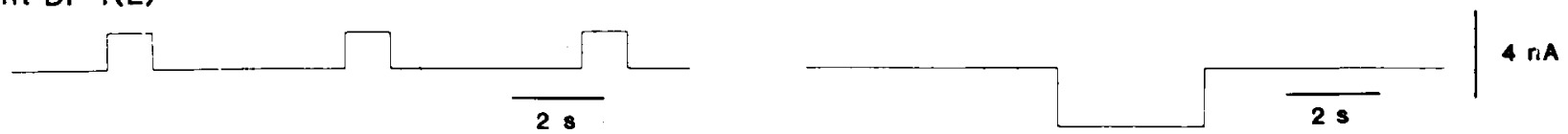

Figure 6. The inhibitory effect of $\mathrm{Dl}-1$ on the contralateral VE-4 is mediated at least in part by VI-2 which is electrically coupled to DI-1. A, Schematic drawing to illustrate the intracellular electrode placement. B. Three depolarizing current pulses injected into DI-1 (third trace) caused hyperpolarizing responses in the contralateral VE-4 (top trace). Injection of hyperpolarizing current into VI-2 (second trace) resulted in a reduction of the hyperpolarizing response of VE-4. C. Three depolarizing current pulses injected into VI-2 (second trace) caused hyperpolarizing responses in the contralateral VE-4 (top trace). There was almost no change in the response of VE-4 to VI-2 depolarization when DI- 1 was hyperpolarized by current injection. The bottom two traces in $B$ and $C$ show the timing and amplitude of current pulses injected into $\mathrm{Dl}-1$ and $\mathrm{VI}-2$ 


\section{A. INTACT}

1

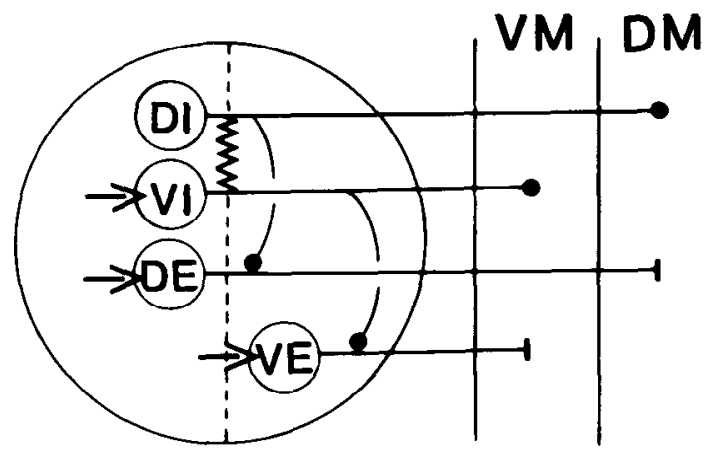

2
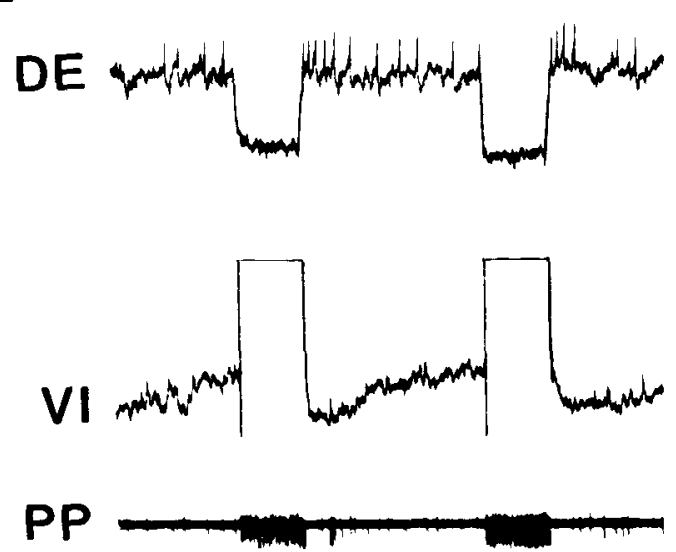

3

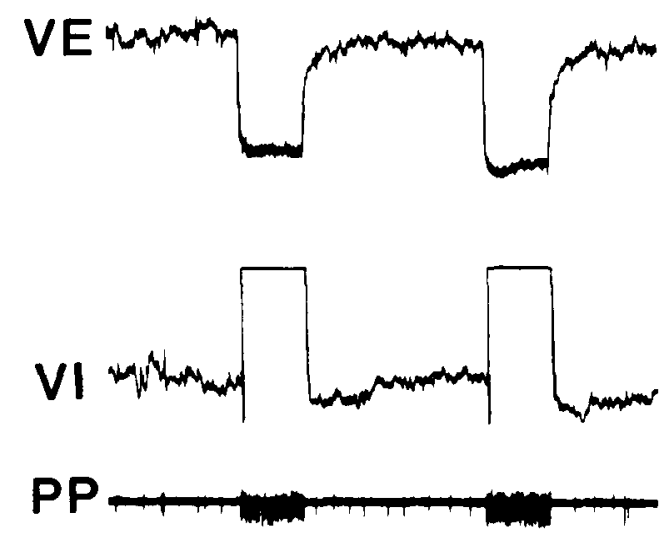

B. DI CELLS ABLATED

1

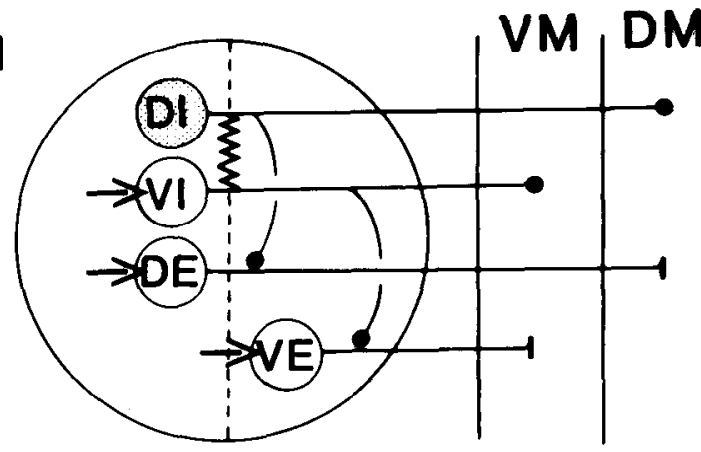

2

DE $10 \mathrm{mV}$
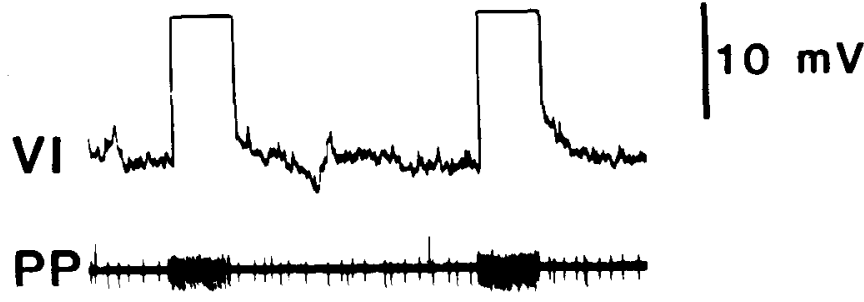

3

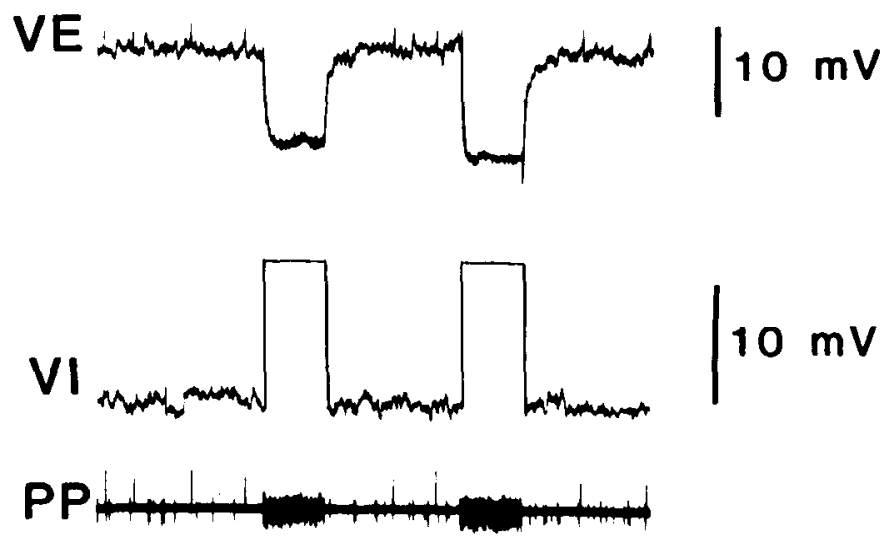

$5 \mathrm{~s}$

Figure 7. Photoinactivation of dorsal inhibitory motor neurons abolishes the inhibitory effect of VI-2 onto DE-3. The effect of depolarizing VI-2 on both the ipsilateral DE-3 and the contralateral VE-4 were compared in an intact ganglion $(A)$ and in the same ganglion following photoinactivation of all dorsal inhibitors $(B)$, as represented in schematic drawings at the top of each panel. (Stippling indicates photoinactivated dorsal inhibitors). In each case a pair of depolarizing current pulses ( $1 \mathrm{nA}$ followed by $2 \mathrm{nA}$ ) was injected into VI-2 (middle trace of each set of recordings). In the intact ganglion this resulted in hyperpolarizing responses in both DE-3 (top trace of A-2) and VE-4 (top trace of $A-3$ ). Following photoinactivation of the dorsal inhibitors, the same intensity of current injection into VI-2 had no effect on DE-3 (top trace of $B-2$ ), whereas the responses in VE-4 (top trace of $B$-3) were essentially unchanged from those recorded in the intact ganglion. The bottom trace of each set of recordings is an extracellular recording from the contralateral posterior posterior peripheral nerve $(P P)$ which contains the axon of $\mathrm{VI} 2$. The tiring rate of $\mathrm{VI}-2$ indicates that the effect of the depolarizing current injected into $\mathrm{VI}-2$ remains nearly the same before and after photoinactivation of the dorsal inhibitors. 

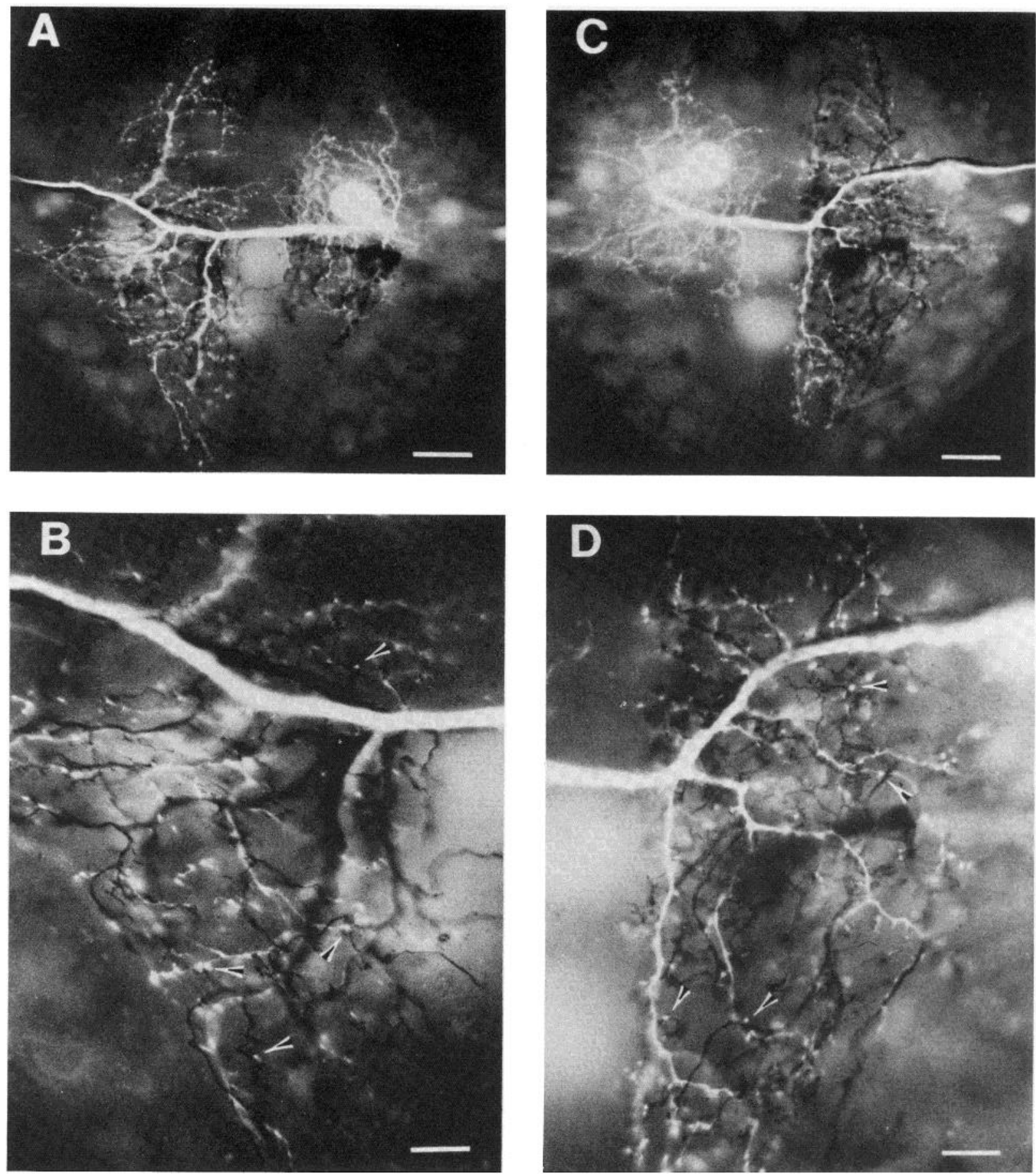

Figure 8. Pairwise fills of excitatory and inhibitory motor neurons demonstrating overlap of the processes of the motor neurons. In $A$ and $B$, DE- 3 is filled with $\mathrm{HRP}$ and $\mathrm{Dl}-1$ is filled with Lucifer Yellow. $B$ is a higher magnification of the left side of the ganglion shown in $A$. In $C$ and $D$, VE-4 is filled with HRP and VI.2 is filled with Lucifer Yellow. $D$ is a higher magnification of the right side of the ganglion shown in $C$. Arrowheads in $B$ and $D$ point out inhibitory motor neuron varicosities which are in close apposition to excitatory motor neuron processes. Scale bars: $A$ and $C, 50 \mu \mathrm{m} ;$ and $B$ and $D, 20 \mu \mathrm{m}$. Anterior is toward the bottom of each photograph.

depolarizing current pulses injected into DI-1 elicited depolarizing coupling potentials in the ipsilateral VI-2 and concomitant hyperpolarizations in the contralateral VE-4. Injection of current to hyperpolarize VI-2 during a DI-1 depolarization reduced the hyperpolarizing potential in VE-4 to about half the amplitude of the preceding and following responses (Fig. $6 B$ ). Thus, the $\mathrm{Dl}-1$ hyperpolarization of VE-4 appears to be by way of VI-2. The response in VE-4 to DI-1 depolarization is not entirely blocked by hyperpolarizing VI-2 probably because only one of four VIs is being directly hyperpolarized; for, although the VIs are all weakly electrically coupled, it is unlikely that they are all completely inactivated by current injected into only one cell. Conversely, none of the inhibition of VE- 4 by VI-2 occurs by way of Dl-1, since even larger hyperpolarizing currents injected into $\mathrm{DI}-1$ had no effect on the inhibitory response in VE-4 caused by VI-2 (Fig. 6C).

In a second set of experiments, the hyperpolarizing effect of VI-2 onto DE-3 was abolished by photoinactivating all of the dorsal inhibitory motor neurons (Fig. 7). Depolarizing current pulses injected 


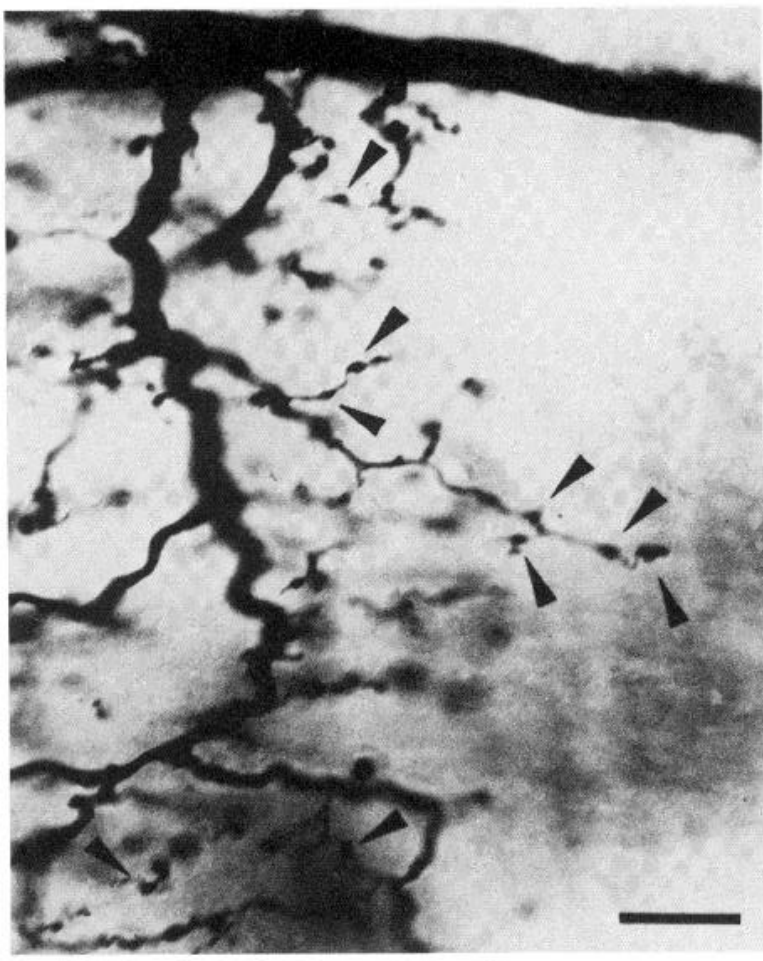

Figure 9. HRP fill of DI-1 reveals numerous varicosities on processes which branch from the main process on the side of the ganglion contralateral to the cell body. A number of these varicosities are indicated by the arrowheads. Scale bar, $20 \mu \mathrm{m}$.

into VI-2 initially caused substantial hyperpolarizations in both DE-3 and VE-4 (Fig. 7A). Then all DIs (both pairs of DI-Is and DI-102s, the latter being the only other identified pair of dorsal inhibitors (Stuart, 1970; Ort et al., 1974)) were filled with Lucifer Yellow and illuminated with blue light for $30 \mathrm{~min}$. Following this treatment, the same level of current injected into VI-2 no longer caused a hyperpolarizing response in DE-3 (Fig. 7B). Current injected into VI-2 still evoked a hyperpolarizing response in VE-4 comparable in strength to that which occurred prior to photoinactivation of the dorsal inhibitors. These results support the hypothesis that the inhibitory effect of VI-2 onto DE-3 (and presumably that of DI-1 onto VE-4) is mediated by the electrical coupling between $\mathrm{Dl}-1$ and $\mathrm{VI}-2$.

\section{Anatomy}

The physiological data presented above do not rule out the possibility that an interposed neuron mediates the interactions between DI- 1 and DE-3 and between VI-2 and VE-4. Therefore, we examined the anatomical relationships betwen these neurons to determine whether direct contacts might occur. This was done by injecting Lucifer Yellow into one motor neuron and HRP into another, and then observing them with the light microscope (see "Materials and Methods"). Processes of DI-1 and DE-3 do indeed occupy similar regions within the ganglion (Fig. $8 A$ ). Each neuron has a tuft of fine processes which arises from the major process near the cell body. In addition, the major processes of the two cells branch on the side of the ganglion contralateral to their somata, giving rise to a field of overlapping processes. In some preparations the primary branches were seen to twist around one another. The secondary and tertiary processes in this area are also in close proximity. In particular, there is an abundance of distinct swellings or varicosities on the contralateral processes of Dl-1 (Fig. 9) The overall varicose appearance of these processes is strikingly different from those of both the ipsilateral processes of DI-1 and DE-3 and the contralateral processes of DE-3. Such varicosities, when examined at higher magnification (Fig. 8B), appear to contact DE-3 and are therefore likely sites of synaptic interaction. These varicosities also were found on the contralateral processes of VI-2, as well as on the other inhibitory motor neurons of which the anatomy was examined. On sensory neurons, similar varicosities have been shown to be the sites of presynaptic specializations (Muller and McMahan, 1976).

The morphology of VE-4 differs from that of the other excitatory motor neurons. Its axon exits by an ipsilateral peripheral nerve, whereas the axons of all other motor neurons exit by contralateral peripheral nerves. In addition, all of its processes are contained entirely in the half of the ganglion ipsilateral to its soma (Fig. $8 \mathrm{C}$ ). Each VI-2 inhibits the VE-4 having a soma contralateral to its own and in which the peripheral field is on the same side of the leech body as its own (Fig. 1). Pairwise fills of VI-2 and the contralateral VE-4, which it inhibits, revealed a geometrical relationship between these two cells which was different from that found between DI-1 and DE-3 (Fig. $8 \mathrm{C}$ ). In this case only the contralateral processes of $\mathrm{VI}-2$ are in the vicinity of VE-4 processes, and varicosities thereon are in close anatomical proximity with VE-4 processes (Fig. 8D).

We attempted to verify whether the putative contacts seen between inhibitory and excitatory motor neurons in whole mounts were true synaptic contacts. This was done by differentially marking pairs of motor neurons for examination at the ultrastructural level (see "Materials and Methods"). DI-1 was filled with Imposil and DE-3 was filled with HRP. The ultrastructural features of chemical synaptic contacts between leech neurons are generally accepted to be the following: (1) an accumulation of vesicles in the presynaptic process; (2) a presynaptic density; (3) a cleft between the membranes of apposing processes which is wider and darker than the space between processes on either side of the synapse; (4) straightened, parallel membranes at the cleft; and often (5) a triad arrangement of the processes with either one presynaptic process contacting two adjacent postsynaptic processes or two adjacent presynaptic processes contacting one postsynaptic process (Muller and McMahan, 1976; Muller, 1979). However, the labeling of neurons with electron-dense markers masks the presynaptic density which, even in unlabeled leech neurons, is not so prominent as it is, for example, at the vertebrate neuromuscular junction. Thus, the presynaptic density cannot be used as an identifying feature of synaptic contacts in labeled leech neurons. A similar problem was encountered in the recognition of synaptic ultrastructure in HRP-labeled Aplysia neurons (Bailey and Chen, 1983). A random sampling of numerous thin sections cut through ganglia containing marked motor neuron pairs was examined in the region where contacts between DI-1 and DE-3 were expected (i.e., in the area of overlapping DI-1 and DE-3 processes on the side of the ganglion contralateral to the somata of the two cells). In this region, HRP-filled processes were commonly adjacent to Imposil-filled processes (Fig. 10), several of which fulfilled some, but not all, of the morphological criteria used to identify synapses. For example, shown in the micrograph of Figure 10 is one putative synaptic contact, judging from the accumulation of vesicles in an Imposil-labeled DI-1 process (Fig. 10, arrow) at the point where it makes contact with an HRP-labeled DE-3 process; however, the structure of the membranes here is not visible so that the site cannot be identified unequivocally as a synaptic contact. Some apparent clefts (wider gaps with straightened, parallel membranes) were found, but these lacked presynaptic vesicles (Fig. 11). This site also displays the triad arrangement of processes typical of the ultrastructure of leech synapses. The scarcity of vesicles may have been due, in part, to the presence of Imposil in the presynaptic cell. Disruption of intracellular structure was apparent in some Imposil-filled processes, as evidenced by empty spaces in them (Fig. 10). This is similar to the disruption that also results from HRP labeling. Vesicles were scarce in Imposil-filled processes, although organelles such as mitochondria seemed to remain intact. Hence, the electron microscopic studies demonstrated close contacts between DI-1 and DE-3 and strongly suggested, but did not absolutely confirm, the presence of synapses between these two motor neurons. 


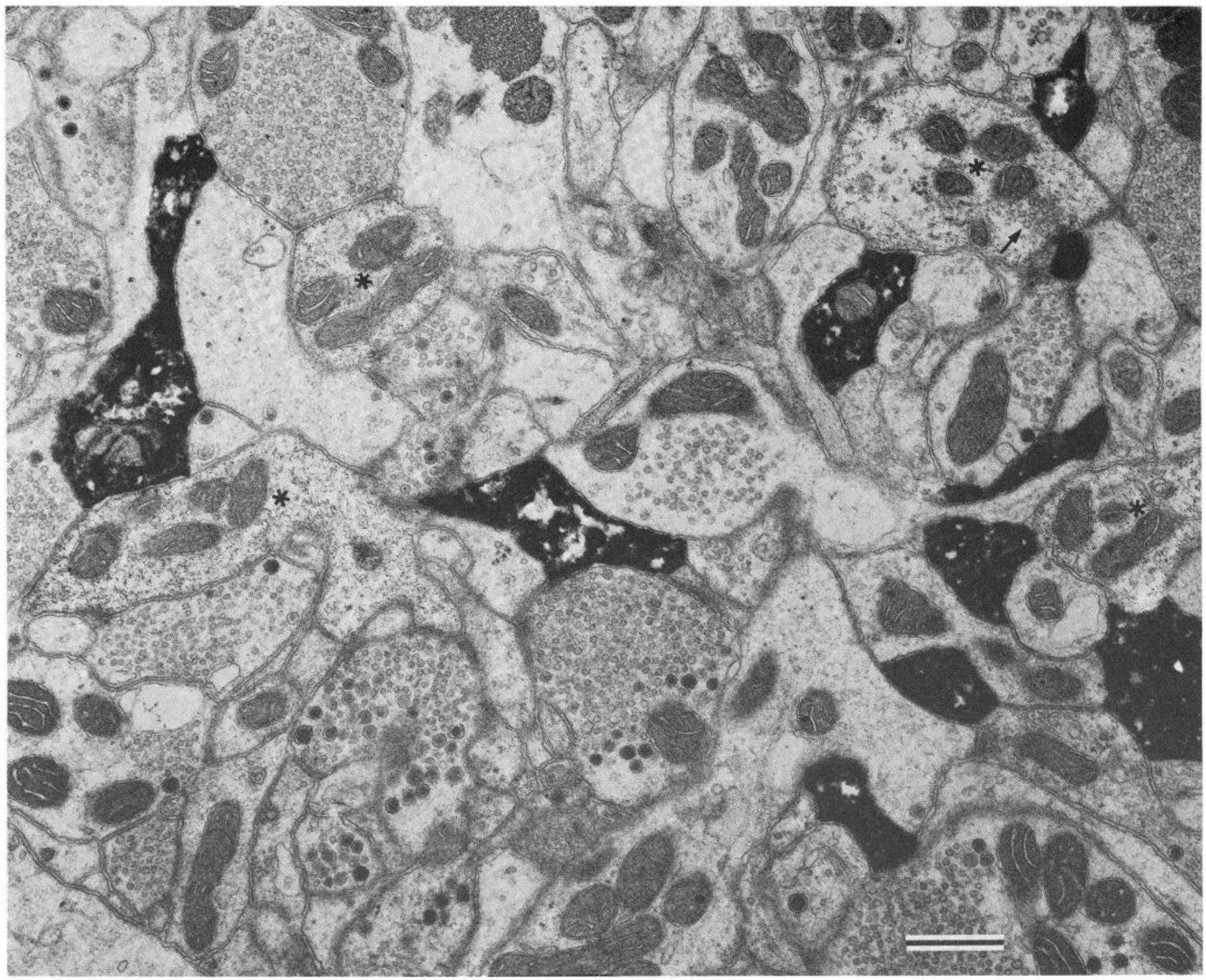

Figure 10. Electron micrograph of a section from a ganglion in which DI-1 was labeled with Imposil and DE-3 was labeled with HRP. This section was taken from the side of the ganglion contralateral to the somata of the two marked neurons. In this micrograph there are $10 \mathrm{HRP}$-labeled processes (each containing black reaction product) and four Imposil-labeled processes (each marked here with an asterisk). There are seven sites at which HRP-labeled and Imposil-labeled processes abut one another. At one site (arrow) is an accumulation of presynaptic vesicles in Dl-1. Scale bar, $0.5 \mu \mathrm{m}$.

\section{Non-impulse-mediated transmission}

The time course of the postsynaptic hyperpolarizing potentials in the excitors closely follows the presynaptic depolarizing membrane potential shifts caused by current injection into the inhibitors (Figs. 3 and 4). This suggests that this inhibition is mediated primarily by tonic transmitter release, rather than through impulse-mediated synaptic transmission. It was difficult, however, to distinguish the effects of graded release from the summed effects of impulse-mediated release, because even small changes in membrane potential in an inhibitory motor neuron evoked changes in its firing rate. We wanted to determine whether transmission from inhibitory to excitatory motor neurons could occur in the absence of impulses. In leech neurons impulses are tetrodotoxin-insensitive, thereby precluding the most common method used for abolishing sodium-dependent impulses. It was therefore necessary to devise other methods for this purpose. Three different experimental manipulations were employed.

Nerve crush. The posterior peripheral nerve root (from which both PP and DP nerves branch) was pinched with forceps near the point where the nerve exits the ganglion. In some ganglia this procedure abolished impulses recorded in the somata of motor neurons that sends axons out the posterior nerve, including those of the inhibitors $\mathrm{DI}-1$ and VI-2. Presumably this is because the region of membrane capable of generating impulses in these motor neurons is limited to the axon in the nerve and was thus eliminated by the crush. In other preparations it was necessary to crush further into the ganglia, sometimes halfway into the contralateral side of the ganglia, to eliminate the impulses in these motor neurons. Apparently, the impulse-generating membrane of these motor neurons extended further into the ganglia in these preparations. The transmission coefficient (defined above) of the inhibitory-to-excitatory motor neuron connections were determined before and after crushing the posterior nerve. In the example illustrated (Fig. 12), the transmission coefficient between VI-2 and VE-4 decreased from 0.30 to 0.15 , a reduction of $50 \%$ due to a crush that extended halfway into the contralateral side of the ganglion. This $50 \%$ reduction was the largest change in postsynaptic potential brought about by the crush in six similar experiments (three on VI-2, VE-4 pairs and three on DI-1, DE3 pairs), and much of this decrement could have occurred because of damage to neuropilar processes. Thus, impulses in these inhibitory 


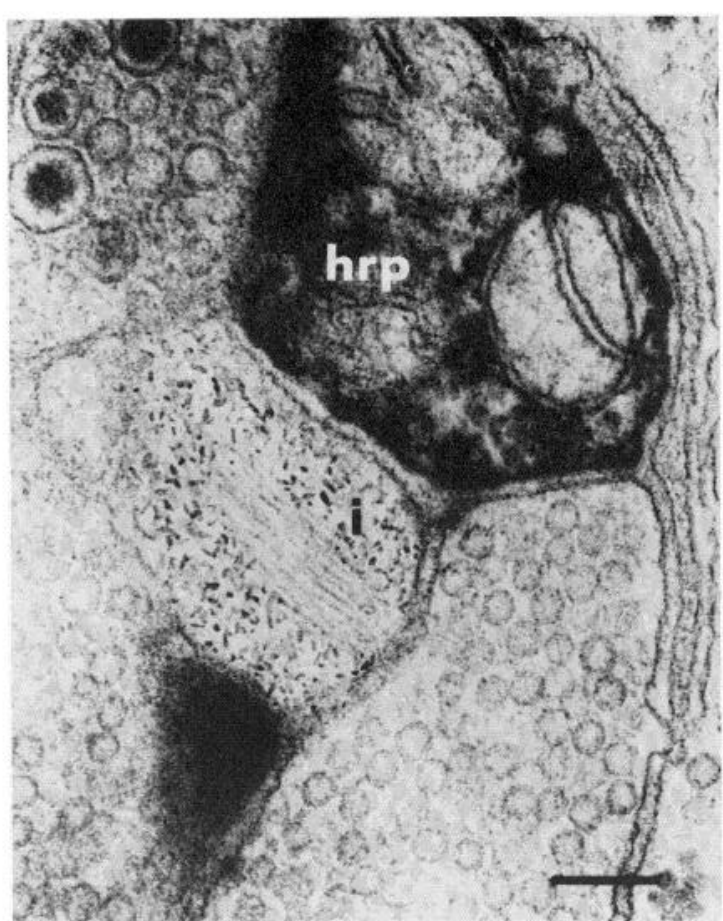

Figure 11. Electron micrograph showing a process of DI-1 filled with Imposil (i) and an adjacent process of DE-3 filled with HRP (hrp). A second smaller HRP-labeled process is also visible in the lower half of the micrograph Scale bar, $0.2 \mu \mathrm{m}$.

motor neurons can account for no more than $50 \%$ of the synaptic transmission.

$\mathrm{Na}^{+}$-free saline. Bathing ganglia in sodium-free saline (in which sodium chloride was replaced with Tris- $\mathrm{HCl}$ ) also eliminated impulses in the motor neurons. In normal saline, motor neurons typically had resting potentials of 40 to $50 \mathrm{mV}$. In Tris- $\mathrm{HCl}$ saline, the membrane potential hyperpolarized by 5 to $25 \mathrm{mV}$ (Fig. 13A). This hyperpolarization occurred rapidly and was completely reversible. It was observed in every identified cell type tested, including sensory neurons, motor neurons, and interneurons. Along with the increase in membrane potential, impulse activity ceased in all motor neurons, both as recorded from the somata and in the extracellular recordings obtained from axons in peripheral nerves. Furthermore, cells could not be caused to fire impulses by injection of even large depolarizing currents.

Current pulses were injected into $\mathrm{Dl}-1$ in preparations bathed in sodium-free saline to assess the efficacy of synaptic transmission in the absence of nerve impulses. As illustrated in Figure 13B-2, the time course of the hyperpolarizations induced in DE-3 by these current pulses is slowed, and greater presynaptic currents are required to achieve a given level of hyperpolarization in the postsynaptic neuron. The apparent decrease in the strength of the interaction may be attributable to the $15-\mathrm{mV}$ hyperpolarization induced in the motor neurons by the Tris- $\mathrm{HCl}$ saline solution, which brings $\mathrm{DE}-3$ closer to the reversal potential for the postsynaptic inhibitory response. Nevertheless, these experiments show unequivocally that the DI-1 to DE-3 interaction can occur without nerve impulses.

High $\mathrm{Ca}^{2+} /$ high $\mathrm{Mg}^{2+}$ saline. Ganglia were bathed in $20 \mathrm{~mm} \mathrm{Ca}^{2+}$ $10 \mathrm{mM} \mathrm{Mg}^{2+}$ saline in order to raise the threshold for impulse generation. This resulted in suppression of ongoing firing in all neurons in the ganglion. The motor neurons were still capable of generating impulses when stimulated, but only at abnormally high levels of depolarization. Low intensities of current (e.g., 0.2 to 0.5 $\mathrm{nA}$ ) injected into the inhibitory motor neurons resulted in substantial depolarizations but very few impulses. Because impulse activity in other neurons was suppressed, the impulses of a stimulated inhibi- tory motor neuron were the only ones that occurred in extracellular recordings from peripheral nerves. This allowed reliable monitoring of impulses from a depolarized inhibitor. In the example shown (Fig. 14), $0.5 \mathrm{nA}$ of current injected into VI-2 caused a significant depolarizing shift in the membrane potential of VI-2, but only one impulse occurred. Although the single impulse was significantly delayed relative to the onset of the membrane potential depolarization caused by current injection, the postsynaptic hyperpolarizing response in VE-4 followed the time course of the presynaptic depolarization, commencing before the occurrence of any impulses. Clearly, graded release of transmitter accounts for the postsynaptic response under these conditions.

\section{Discussion}

Monosynapticity. The common physiological tests used to determine whether a chemical synaptic connection is monosynaptic or polysynaptic are limited to those functional interactions in which a presynaptic impulse elicits a distinctive postsynaptic potential (PSP) (Berry and Pentreath, 1976). Monosynaptic connections are typically characterized by: (1) a PSP which reliably follows the presynaptic impulse at a short and constant latency, (2) concomitant changes in PSP duration with changes in the duration of the presynaptic impulse, and (3) survival of the one-to-one relationship between the PSP and the presynaptic impulse in elevated concentrations of divalent cations (which would raise the firing threshold of any putative intermediate impulse-generating neuron and thereby result in failure) (Nicholls and Purves, 1970; Berry and Pentreath, 1976). Even so, none of these tests can distinguish between a monosynaptic connection and a polysynaptic pathway which includes either an electrically coupled interneuron or an interneuron which uses graded release of neurotransmitter (Berry and Pentreath, 1976). That this is more than an academic issue has been documented recently by the demonstration of an electrically coupled interneuron between two neurons that appeared, from rigorous physiological tests, to be directly connected (Muller and Scott, 1981).

In addition, there are other functional interactions for which there are no physiological means for determining conclusively the directness of a connection. This is particularly true when the presynaptic neuron of concern uses, primarily or entirely, graded release of neurotransmitter (Burrows and Siegler, 1978). A similar and perhaps more general problem occurs for connections in which the impulseevoked PSPs occur too far from the postsynaptic recording electrode to be detected as individual events. In fact, our attempts to analyze the connections of the inhibitory to excitatory longitudinal muscle motor neurons in leech appear to be complicated by a combination of these two factors. Measurements of synaptic latency indicate that the connections are probably direct. This is true whether the measurements are made between VI-2 impulses and the IPSPS which they elicit in VE-4, or between the onset of presynaptic voltage changes in VI-2 or DI-1 caused by square-pulse current injection and the onset of the resultant postsynaptic voltage change in VE-4 or $D E-3$. In addition, the efficacy of the connections (judging from the transmission coefficients which we measured between DI-1 and DE3 and between VI-2 and VE-4) suggest direct connections. However, the four polysynaptic pathways shown schematically in Figure 15 also potentially account for the short-latency inhibition between inhibitory and excitatory motor neurons provided that the connections were strong.

Despite the one-to-one relationship between VI-2 impulses and VE-4 IPSPS, the physiological tests for monosynapticity described above for impulse-generating neurons are inconclusive. For example, the elevated divalent cation test for monosynapticity is not definitive because the increased concentration of calcium ions also increases transmitter release. The depolarization used to elicit presynaptic impulses from VI-2 under these conditions seems to cause a larger than usual amount of graded transmitter release, during which an impulse-evoked IPSP becomes undetectable (Fig. 14).

Because the inhibitory to excitatory motor neuron connections 


\section{Cell VE-4(R)}

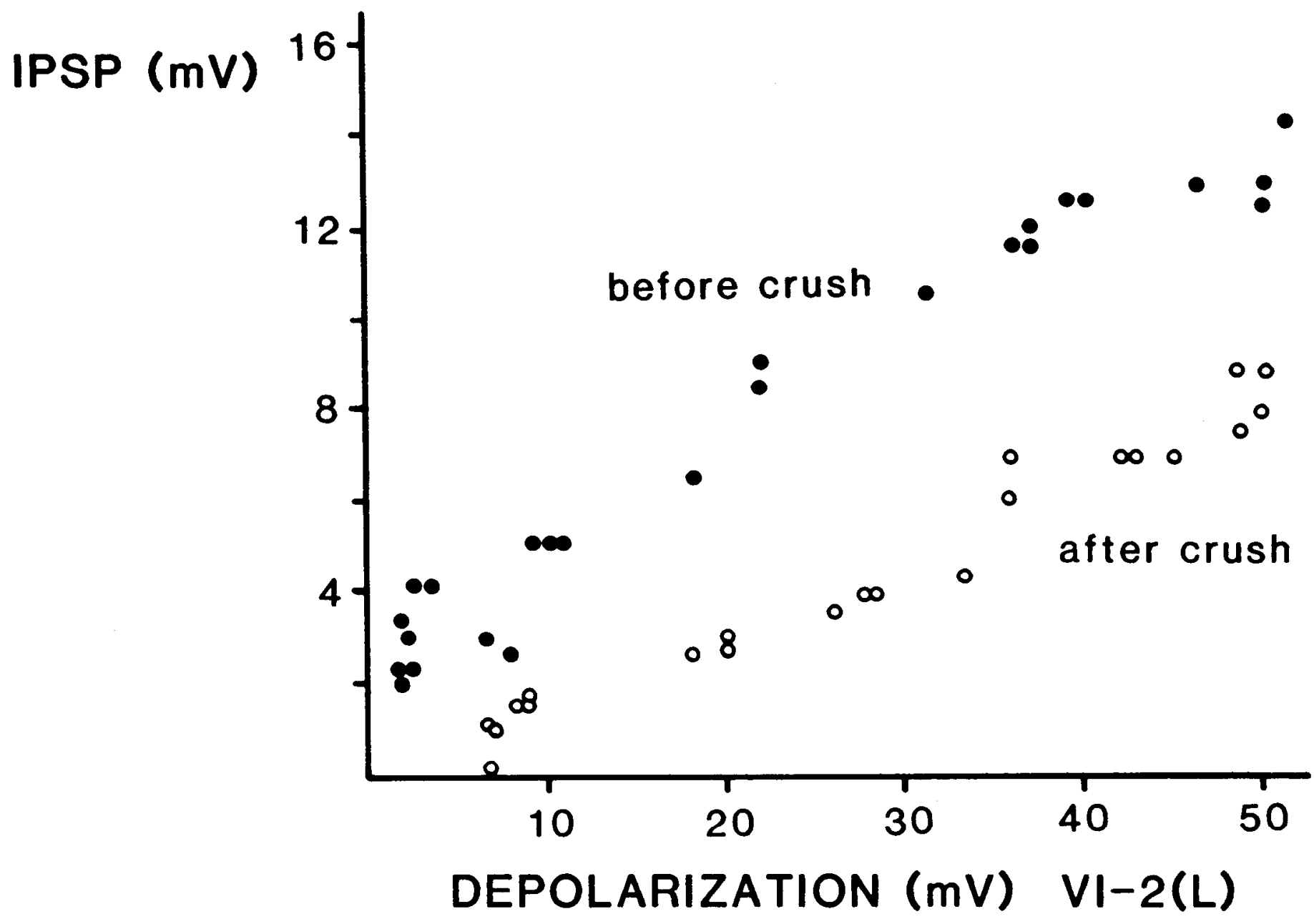

Figure 12. Relationship between presynaptic membrane potential depolarization of VI-2 (caused by current injection) and postsynaptic hyperpolarizing responses in VE-4 before (O) and after (O) elimination of the impulse-generating region of the axon of VI-2. The axon of VI-2 was pinched off proximal to the impulse-generating region using a forceps between the times that data for these two curves were obtained

remain functional in sodium-free saline, not only can it be concluded that graded transmitter release occurs from the inhibitors, but also, with regard to the directness of the connections, it can be concluded that: (1) there are no intermediate impulse-generating neurons between the inhibitors and excitors (unless they use calcium impulses), and (2) there are no excitatory chemical synapses involving increased sodium conductance excitatory PSPS anywhere in the pathway, such as might be required for putative pathways $A$ and $B$ of tigure 15.

Anatomy. One means available for distinguishing between a monosynaptic connection and a polysynaptic pathway which includes an unidentified intercalated, electrically coupled neuron (Fig. $15, C$ and $D$ ) is through the use of anatomical methods. A prime example of the success of this approach has been provided by Muller and Scott (1981), who revealed a physiologically undetectable, electrically coupled interneuron between two neurons thought to be monosynaptically connected (the $T$ cell and the $S$ cell in leeches). They observed the coupling interneuron after it filled with Lucifer Yellow which had beers irijected into the S cell. Furthermore, by filling both $T$ and $S$ cells simultaneously with HRP, they demonstrated that no monosynaptic connections were possible between
$T$ and $S$ cells because the two neurons were not in contact with one another

The light microscopy evidence which we have obtaned is consistent with the hypothesis that the short-latency connections between DI- and DE-3 and between VI-2 and VE-4 are monosynaptic. Both pairs of cells were examined at the light microscope level, which revealed close appositions between processes of the inhibitory and excitatory motor neurons in both cases. At the ultrastructural level, examination of the anatomical relationship between Di-1 and DE-3 revealed many processes of the two cells in direct contact with one another. However, we have not located any examples of contacts which strictly fulfill all of the ultrastructural criteria generally accepted as identifying features of leech synapses (Muller, 1979). This could be due in part to the disruption of vesicles by the presynaptic marker, Imposil, which may have precluded our recognition of some actual sites of synaptic contact. However, it is our impression that, although adjacent processes are quite common between $\mathrm{DI}-1$ and DE-3, the actual sites of synaptic specializations between these two neurons, if they exist, must be quite small. This has been shown to be so for Aplysia sensory neurons in which the synaptic active zones were found, by electron microscopic serial 
A

$\rightarrow$ Tris $\mathrm{HCl}$

$\rightarrow$ Ringer

DI-1(R)

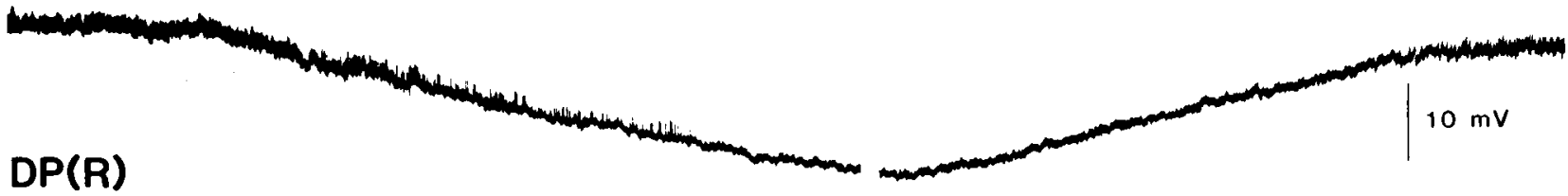

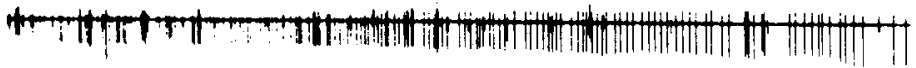

$20 \mathrm{~s}$

B-1 B-2

Ringer

Tris $\mathrm{HCl}$

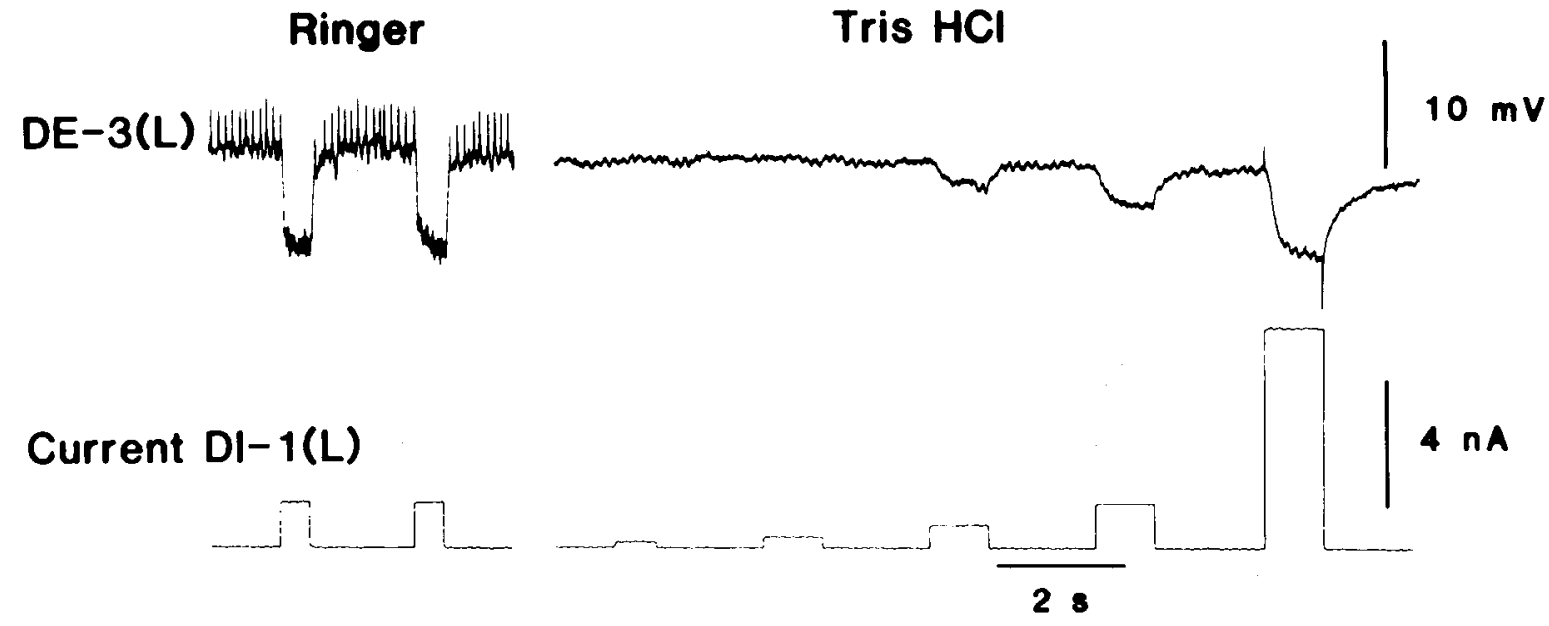

Figure 13. Synaptic transmission in sodium-free saline. A, Simultaneous recordings from Dl-1 and a dorsal posterior peripheral nerve (DP). At the time indicated by the left end of the first arrow, the bathing solution was changed from normal saline to sodium-free saline (Tris-HCl). This saline change caused a rapid hyperpolarization in $\mathrm{DI}-1$ and brought about a cessation of recorded nerve impulses in the DP nerve. At the time indicated by the left end of the second arrow, the preparation was perfused with normal saline. The presence of normal saline caused the cell membrane potential to return rapidly to its control level. Impulse activity returned in the DP nerve with a slight delay (not shown). $B$, Synaptic transmission in sodium-free saline. Current pulses injected into $\mathrm{DI}-1(\mathrm{~L})$ (lower trace) continued to evoke $\mathrm{DE}-3(\mathrm{~L})$ hyperpolarizations (upper trace) in Tris- $\mathrm{HCl}$ saline $(B-2)$, although the synaptic potentials are smaller than in the controls $(B-1)$. Two minutes of the record were excised at the gap in the traces of $A$.

sections, to occupy only a small area of the synaptic terminals (Bailey et al., 1981). Such serial sectioning of leech ganglia, however, revealed only a few possible synaptic specializations between the heart pattern-generating interneurons and the heart oxcitatory motor neurons (L. Tolbert, personal communication), which according to other criteria, were judged to be monosynaptically connected (Calabrese, 1977). It is possible, therefore, that leech synapses are structurally different or less defined than vertebrate synapses, and thus more difficult to distinguish.
We have attempted, for the first time, to intracellularly inject neurons with Imposil, a solution of iron particles, which can be distinguished in electron micrographs and thus be used as a second cellular marker in conjunction with HRP (Olsson and Kristensson, 1978). It is a great advantage that Imposil can be intracellularly injected using the same procedure of pressure injection as for HRP. However, there are three limitations on the use of this marker. First, although histochemical techniques exist to reveal the Imposil in wholc mounts (Olsson and Kristensson, 1978; Nguyen-Legros et al., 


\section{VE-4(R)}

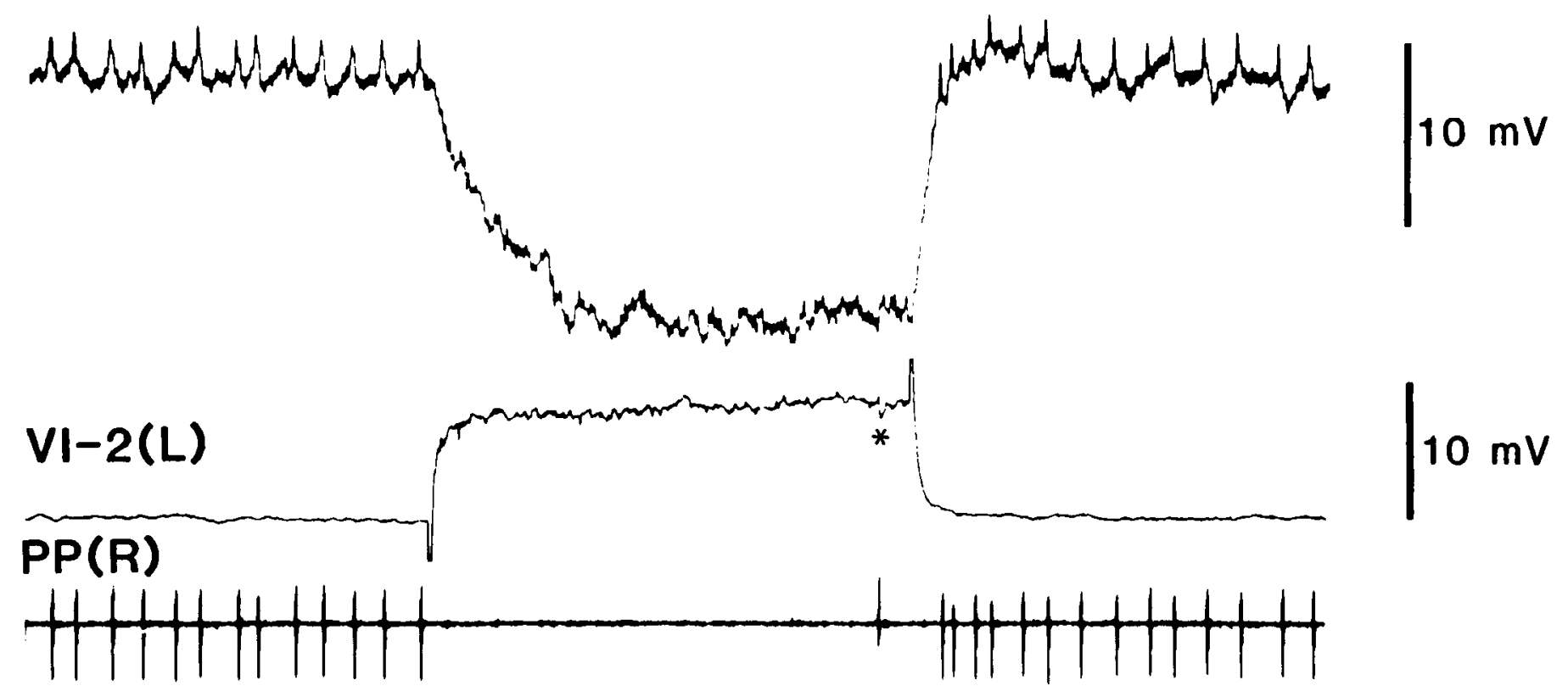

$1 \mathrm{~s}$

Figure 14. Inhibition of VE-4 (top trace) by the contralateral VI-2 in $20 \mathrm{mM} \mathrm{Mg}{ }^{2+}, 10 \mathrm{mM} \mathrm{Ca}^{2+}$ saline. Impulses in the axons of the two motor neurons appear in the extracellular recording from the posterior posterior peripheral nerve (PP) (lower trace). The high $\mathrm{Ca}^{2+} / \mathrm{high}^{\mathrm{Mg}} \mathrm{Mg}^{2+}$ saline raises the firing threshold of the cells. (VE-4 is continuously depolarized by current injection.) VI-2 is depolarized for $2 \mathrm{sec}$ by injecting 0.5 nA of current. This resulted in a substantial DC shift in VI-2 membrane potential but only one impulse occurred (indicated in the intracellular record by an asterisk). The hyperpolarizing response in VE4 follows the time course of the depolarization of VI-2, commencing before any VI-2 action potentials occur.

1980 ), they are incompatible with the preparation of the tissue for electron microscopy. Thus, the success of an intracellular injection with this marker cannot be judged in the whole mount prior to preparation for electron microscopy, as can be done with HRP. Second, Imposil may cause disruption of intracellular organelles, such as vesicles. Third, unlike the enzyme HRP, which produces many molecules of electron-dense reaction product resulting in a dark, homogeneously distributed stain, each Imposil particle produces a single image so that this marker is not as easily detected as the reaction product of HRP. Thus, the detection of Imposil in thin sections requires scanning at relatively high magnifications $(X$ 10,000 to $\times 15,000$ ). However, since we were searching for adjacent HRP. and Imposil-filled processes, sections were scanned first at low magnification for HRP-filled processes and then examined further for Imposil-filled processes. This method of scanning proved quite satisfactory for our purposes.

Non impulse-mediated synaptic transmission. In many types of neurons the propagation of regenerative impulses is the means by which information received by the neuron is transferred along cablelike processes (the axons) to presynaptic terminals. Impulses are required because the analogue signals are effective only over relatively short distances. In neurons that do not generate impulses, chemical synaptic transmission can occur only by way of graded release of neurotransmitter. Although a few primary or secondary sensory neurons have cable properties (such as large diameters and high membrane resistances) which allow passive spread of analogue signals over relatively long distances (e.g., loannides and Walcott, 1971; Shaw, 1972), most non-spiking neurons are local interneurons which transfer information over short distances (e.g., Werblin and Dowling, 1969; Pearson and Fourtner 1975; Burrows and Siegler, 1978). In the lobster, central interactions between motor neurons are involved in the generation of patterned motor output from the stomatogastric ganglion. Although these motor neurons generate impulses, it appears that graded release of neurotransmitter plays a major role in the central interactions of pattern generation, and that the predominant function of the impulses is to mediate transmitter release from the peripheral terminals at the neuromuscular junctions (Raper, 1979; Graubard et al., 1983).

All three methods used in this study to block impulse production also affect synaptic transmission. Removing the impulse-generating portion of the inhibitory motor neuron by crushing the appropriate nerve at the edge of the ganglion may also eliminate some of the synaptic region of the motor neurons. Furthermore, this procedure increases the input resistance of both the pre- and postsynaptic neurons since the entire axon distal to the crush (a current sink) is effectively eliminated from both cells. The loss of some of the synaptic region following the crush would be likely to result in an underestimate of the efficacy of transmission without impulses, whereas the increased input resistance would result in an overestimate. Sodium-free saline also reduces the efficacy of synaptic interactions. In large part this reduction appears to result from the substantial hyperpolarizations associated with the use of sodiumfree saline in the leech. High $\mathrm{Ca}^{2+} /$ high $\mathrm{Mg}^{2+}$ saline potentiates synaptic transmission above normal, presumably because the $\mathrm{Ca}^{2+}$ concentration is 10 times higher than normal and twice that of the $\mathrm{Mg}^{2+}$ concentration, whereas usually the concentrations are equal. This may result in an overestimate of the efficacy of impulseindependent transmission. For these reasons, we cannot determine the quantitative contribution of graded versus impulse-medidated transmitter release between inhibitors and excitors, but we can 

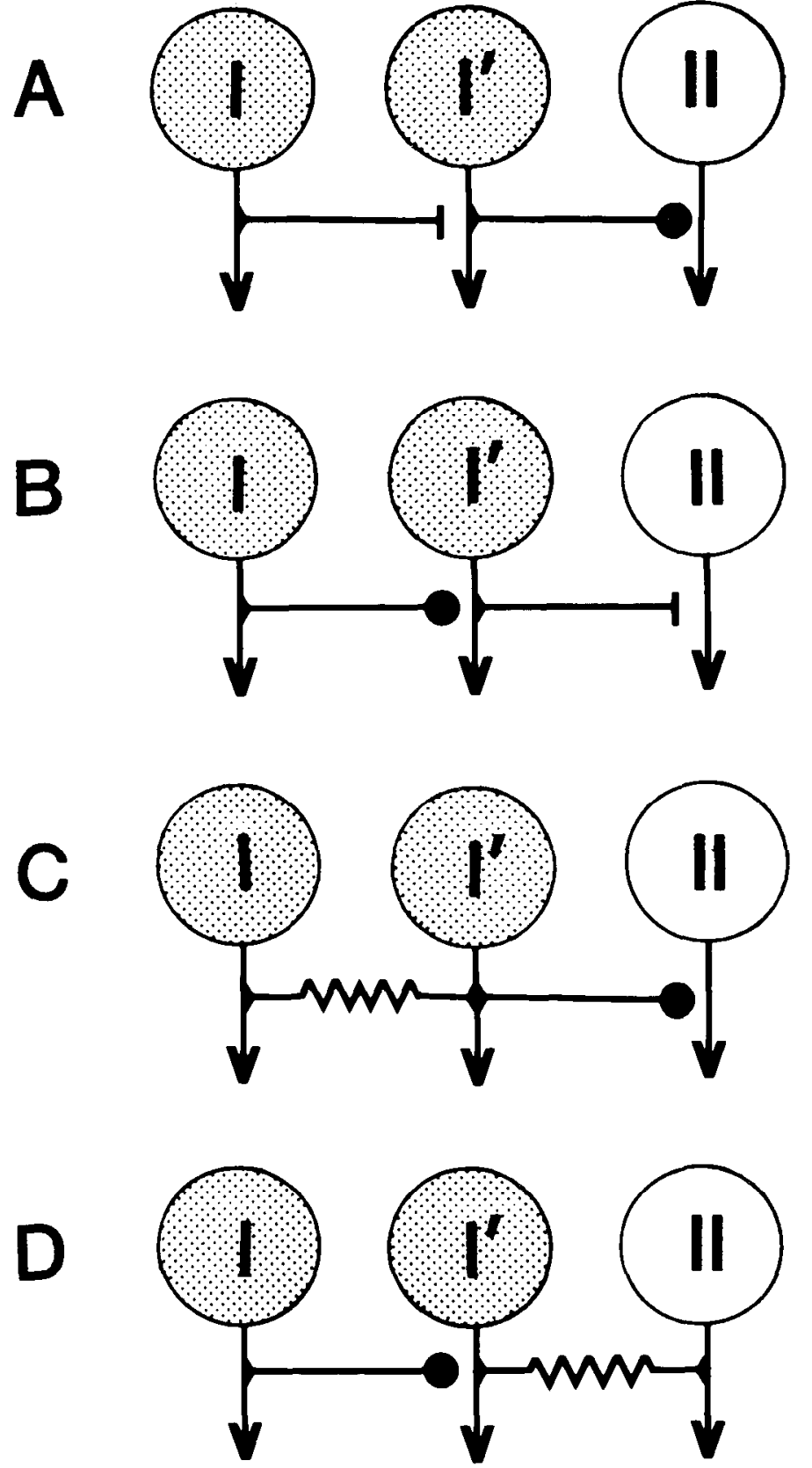

Figure 15. Schematic representation of four polysynaptic pathways which could appear by all available physiological tests as monosynaptic connec tions between neurons I and II. Symbols for connections are: $\dashv$, excitatory chcmical; $\longrightarrow$, inhibitory; 1 -, electrical. Stippling indicates neurons which release neurotransmitter as a graded function of membrane potential. Pathways $C$ and $D$ would appear to be monosynaptic even if $I^{\prime}$ were an impulse gerieraling neuron.

conclude that under three different experimental conditions synaptic transmission does occur in the absence of impulses.

The function of connections among motor ncurons. In lecchcs, the body undulations of swimming result from alternating contractions of the segmentally iterated dorsal and ventral longitudinal muscles of the body wall. These alternating muscle contrations are caused by antiphasic bursts of impulses in DEs and VEs. In addition, inhibitory motor nouron bursts are interposed between the excitatory motor neuron bursts in the sequence: DE-DI-VE-VI-DE-DI-VE-VI (Kristan and Weeks, 1983). These bursts of impulses arise from membrane potential oscillations in the motor neurons which are driven by the activity of central pattern-generating neurons. Excitatory motor neurons receive phasic excitation and inhibition from the patterngenerating interneurons (Friesen et al., 1978; Poon et al., 1978; Weeks, 1982). In addition, preliminary evidence indicates that the inhibitory motor neurons increase the amplitude of the oscillations in the excitatory motor neurons by providing inhibition which occurs antiphasically to the excitation from pattern generators (B. Granzow, manuscript in preparation). This inhibitory modification of the pattern generator-produced oscillations may be important in determining excitatory motor neuron burst characteristics such as duration or intensity. This remains to be tested.

The electrical coupling between the dorsal and ventral inhibitors is enigmatic only if one attempts to consider a role for it in the swimming behavior. Since these two motor neuron groups oscillate out of phase with one another during swimming, the indirect inhibitory effects on excitatory motor neurons which result from this electrical coupling would not be expressed. However, during other behaviors, the coactivation of ventral and dorsal longitudinal inhibitors (resulting in the simultaneous inhibition of both ventral and dorsal longitudinal excitors) or the coinactivation of both classes of inhibitors (simultaneously releasing both ventral and dorsal excitors from inhibition) would presumably be appropriate. We can speculate that the latter would be the case, for example, during the whole-body shortening phase of leech crawling, wherein there is a coactivation of the dorsal and ventral longitudinal muscles, whereas the former would be appropriate in order to terminate the shortening phase of the crawling behavior.

\section{References}

Bailey, C. H. and M. Chen (1983) Morphological basis of long-term habituation and sensitization in Aplysia. Science 220: 91-93.

Bailey, C. H., P. Kandel, and M. Chen (1981) Active zones at Aplysia synapses: Organization of presynaptic dense projections. J. Neurophysiol. 46: 356-368.

Berry, M. S., and V. W. Pentreath (1976) Criteria for distinguishing between monosynaptic and polysynaptic transmission. Brain Res. 105: 1-20.

Burrows, M. (1979) Graded synaptic interactions between local premotor interneurons of the locust. J Neurophysiol. 42: 1108-1123.

Burrows, M., and M. V. S. Siegler (1978) Graded synaptic transmission between local interneurones and motor neurones in the metathoracic ganglion of the locust. J. Physiol. (Lond.) 285: 231-255.

Calabrese, R. L. (1977) The neural control of alternate heartbeat coordination states in the leech, Hirudo medicinalis. J. Comp. Physiol. 122: 111-143.

Friesen, W. O., M. Poon, and G. S. Stent (1978) Neuronal control of swimming in the medicinal leech. II. Identification of a network of oscillatory interneurones. J. Exp. Biol. 75: 25-43

Graubard, K., J. A. Raper, and D. K. Hartline (1983) Graded synaptic transmission between identified spiking neurons. J. Neurophysiol. 50:508521.

Ioannides, A. C., and B. Walcott (1971) Graded illumination potentials from retinula cell axons in the bug Lethocerus. Z. Vergleich. Physiol. 71: 315325

Kristan, W. B., Jr. and J. C. Weeks (1983) Neurons controlling the initiation, generation and modulation of leech swimming. In The Society for Experimental Biology Symposium XXXVII: Neural Origin of Rhythmic Movements, A. Roberts and B. Roberts, eds., pp. 243-260, Cambridge University Press, Cambridge, UK.

Kristan, W. B., Jr., G. S. Stent and C. A. Ort (1974) Neuronal control of swimming in the medicinal leech. III. Impulse patterns of motor neurons. Comp. Physiol. 94: 155-176.

Macagno, E. R., K. J. Muller, W. B. Kristan, S. A. DeRiemer, R. Stewart, and B. Granzow (1981) Mapping of neuronal contacts with intracellular injection of horseradish peroxidase and Lucifer Yellow in combination. Brain Res. 217: 143-149.

Miller, J. P., and A. I. Selverston (1979) Rapid killing of single neurons by irradiation of intracellularly injected dye. Science 206: 702-704.

Muller, K. J. (1979) Synapses between neurones in the central nervous system of the leech. Biol. Rev. 54: 99-134.

Muller, K. J., and U. J. McMahan (1976) The shapes of sensory and motor neurones and the distribution of their synapses in ganglia of the leech: $A$ study using intracellular injection of horseradish peroxidase. Proc. R. Soc. 
Lond. Biol. 194: 481-499.

Muller, K. J., and S. Scott (1981) Transmission at a "direct" electrical connexion mediated by an interneurone in the leech. J. Physiol. (Lond.) 311: 565-583.

Nguyen-Legros, J., J. Bizot, M. Bolesse, and J. -P. Pulicani (1980) Noir de Diamino benzidine: Une nouvelle methode histochimique de revelation du fer exogene. Histochemistry 66: 239-244.

Nicholls, J. G., and D. Purves (1970) Monosynaptic chemical and electrical connections between sensory and motor cells in the central nervous systern of the leech. J. Physiol. (Lond.) 209: 647-667.

Nicholls, J. G., and D. Purves (1972) A comparison of chemical and electrical synaptic transmission between single sensory cells and a motoneurone in the central nervous system of the leech. J. Physiol. (Lond.) 225: 637-656.

Nicholls, J. G., and B. G. Wallace (1978) Modulation of transmission at an inhibitor synapse in the central nervous system of the leech. J. Physiol. (Lond.) 281: 157-170.

Olsson, T., and K. Kristensson (1978) A simple histochemical method for double labelling of neurons by retrograde axonal transport. Neurosci. Lett. 66: 239-244.

Ort, C. A., W. B. Kristan, Jr., and G. S. Stent (1974) Neuronal control of swimming in the medicinal leech. II. Identification and connections of motor neurons. J. Comp. Physiol. 94: 121-154.

Pearson, K. G., and C. R. Fourtner (1975) Nonspiking interneurons in walking system of the cockroach. J. Neurophysiol. 38: 33-52.

Poon, M. W. O. Friesen, and G. S. Stent (1978) Neuronal control of swimming in the medicinal leech. $V$. Connexions between the oscillatory interneurones and the motor neurones. J. [xp. Biol. 75: 45-63.

Raper, J. A. (1979) Nonimpulse-mediated synaptic transmission during the generation of a cyclic motor pattern. Science 205: 304-306.

Shaw, S. R. (1972) Decremental conduction of the visual signal in barnacle lateral eye. J. Physiol. (Lond.) 220: 145-175.

Stuart, A. E. (1970) Physiological and morphological properties of motoneurones in the central nervous system of the leech. J. Physiol. (Lond.) 209 $627-646$.

Weeks, J. C. (1982) Synaptic basis of swim initiation in the leech. II. Patterngenerating neuron (cell 208) which mediates motor effects of swiminitiating neurons. J. Comp. Physiol. 148: 265-279.

Werblin, F. S., and J. E. Dowling (1969) Organization of the retina of the mudpuppy Necturus maculosus. II. Intracellular recording. J. Neurophysiol. 32: $339-355$. 